\title{
Disconnection from prediction: a systematic review on the role of right temporoparietal junction in aberrant predictive processing
}

Fabio Masina1,\#, Rachele Pezzetta ${ }^{1, \#, ~ S a r a ~ L a g o ', ~ D a n t e ~ M a n t i n i 2 ~}{ }^{2}$, Cristina Scarpazza1,3, Giorgio Arcara1

1 IRCCS San Camillo Hospital, Venice, Italy

2 Research Center for Motor Control and Neuroplasticity, KU Leuven, 3001 Leuven, Belgium

3 Department of General Psychology, University of Padova, Padua, Italy

\# These authors contributed equally: Fabio Masina and Rachele Pezzetta

\section{Abstract}

The right temporoparietal junction (rTPJ) is a brain area that plays a critical role in a variety of cognitive functions. Although many different theoretical proposals tried to explain the ubiquitous role of rTPJ, recent sources of evidence seem to suggest that rTPJ may be a fundamental cortical region related to different kinds of predictions, easily interpreted in light of the predictive processing framework.

This systematic review aims to better investigate the potential role of rTPJ under a predictive processing perspective, providing an overview of cognitive impairments in neurological patients as the consequence of structural or functional disconnections or damage of rTPJ.

Results confirm the involvement of rTPJ across neurological pathologies in almost all tasks, tapping on different cognitive functions. RTPJ, via its connections with other brain networks, would integrate diverse information and update internal models and expectations of the world. Against traditional views of the mind, which tend to focus on specific and separate domains, we argue that the role of rTPJ can be parsimoniously interpreted as being a key hub involved in domain-general predictions.

As discussed here, predictive mechanisms may be impaired in neurological diseases that involve rTPJ and cause a variety of domain-general disorders. This alternative account of rTPJ role in aberrant predictive processing paves new ways for developments for basic research and has relevant clinical implications. Reconceptualizing these modules as emergent phenomena from a set of mechanisms, with prediction-related processing at the core, may open different perspectives, stimulating new hypotheses also in clinical contexts. 


\section{Introduction}

The right temporoparietal junction (rTPJ) is a brain area that plays a critical role in the higher-order cognitive and motor functions that underlie human behavior. A lesion of this area or its disconnection from other brain structures may have several etiologies, ranging from trauma to neurodegenerative diseases. Among them, stroke (Campbell and Khatri, 2020) is the neurological condition for which the role of rTPJ has been more extensively investigated. Indeed, over half of all ischemic strokes occur in the middle cerebral artery territory ( $\mathrm{Ng}$ et al., 2007), which supplies blood to the bilateral TPJ.

The pattern of behavioral symptoms emerging from rTPJ lesions has fostered an extensive clinical interest in this brain structure. Lesions involving rTPJ are often associated with hemispatial neglect (Corbetta and Shulman, 2011), a disorder of attention that may follow right hemisphere stroke in up to $50 \%$ of patients in the acute stage (Vallar and Calzolari, 2018) and related to a difficulty to orientate, report, or respond to stimuli located on the contralesional hemifield. Besides neglect, recent research effort has shown other functional consequences of rTPJ lesions in several neurological disorders (for extensive reviews, see Frucht et al., 2021; Pisella et al., 2011; Vallar, 2007), as spatial and visual impairments, and movement disorders. Thus, rTPJ potentially carries a high clinical significance and its deeper functional understanding could be extremely valuable for clinicians.

The purpose of this systematic review is therefore to elucidate the involvement of rTPJ in human behavior. To this aim, we will investigate the functional role of rTPJ through the analysis of the functional consequences of its direct lesion or of its disconnection from other regions in neurological disorders. We will initially discuss the role of rTPJ according to the most dominant theoretical accounts, and then introduce the predictive processing framework, an overarching and unifying theory that postulates that the core function of the brain is to minimize prediction errors with respect to a generative model of the world (Pezzulo et al., 2021). In this vein, recently rTPJ has been conceived as a key hub of a putative prediction network (Siman-Tov et al., 2019). After presenting a systematic review of the literature linking rTPJ and neurological disorders, results will be interpreted in the light of a predictive processing framework. Implications and advantages of such interpretations will be highlighted, suggesting that impairments associated with this structure may cause aberrant and domain-general predictive mechanisms, rather than fragmented domain-specific cognitive deficits. Future endeavors for basic and clinical research will finally be proposed.

\subsection{Dominant theoretical accounts of rTPJ in cognition}

Anatomically, rTPJ refers to a composite portion of the cortex roughly encompassing the inferior parietal lobule and extending into the superior temporal gyrus. Albeit this 
definition can approximate the location of rTPJ, it does not account for its anatomical and cytoarchitectonic complexity (Bzdok et al., 2013; Caspers et al., 2006; Patel et al., 2019). This review, rather than looking at the anatomical definition of rTPJ, will focus on an integrative theory describing the functional role of this region and the clinical implications for neurological diseases arising from a comprehensive outlook. Thus, with "rTPJ" we will conventionally refer to an associative cortical region near the intersection of the posterior part of the superior temporal gyrus and the ventral part of the supramarginal gyrus, and the lateral occipital cortex (Corbetta et al., 2008).

The activation of rTPJ has been associated with the involvement of a variety of cognitive functions, raising controversy concerning the role of this region (Krall et al., 2015). To date, there is little consensus regarding whether these functions are supported by specific mechanisms/modules, or they result from a common and overarching mechanism. Actually, there is evidence in favor of both functional specialization (Krall et al., 2015; Scholz et al., 2009) and functional overlap (Carter and Huettel, 2013; Corbetta et al., 2008; Geng and Vossel, 2013; Kubit and Jack, 2013).

The functional specialization framework proposes a one-to-one mapping of cognitive mechanisms and brain structures (Scholz et al., 2009).

It has been demonstrated that the posterior portion of rTPJ, which includes the angular gyrus and the terminal part of the superior temporal sulcus, plays a role in mentalizing, a function referring to the ability to infer the mental states of others (Frith et al., 2003). Strictly related to mentalizing, a large body of evidence indicates the involvement of rTPJ in Theory of Mind (ToM), a milestone of the development of social skills, which consists in the construction of inner models of someone else's beliefs (Koster-Hale and Saxe, 2013).

Along a posterior-anterior axis, evidence from a meta-analysis indicates that ToM shows higher activation probability in the posterior part of rTPJ whereas the most anterior portion has been associated with attention (Decety and Lamm, 2007). A large body of evidence shows the role of rTPJ as part of the ventral attentional control network (VAN) including the middle frontal gyrus and the inferior frontal gyrus. According to a dominant theory of rTPJ function, the VAN allows the reorientation of attention to behaviorally relevant and task-related but currently unattended stimuli (Corbetta and Shulman, 2002). The importance of rTPJ in the bottom-up reorientation of attention, which is responsible for stimulus-driven changes in attentional focus, is well supported by the neurological condition of hemispatial neglect. Regardless of motor or sensory deficits, patients with spatial neglect show difficulties in spontaneously reorienting attention to stimulus information in the contralesional visual field. Importantly, damage of rTPJ is frequently linked to the occurrence of spatial neglect (Corbetta and Shulman, 2011), confirming the pivotal role of this structure in reorienting attention. 
In contrast to a fractionation view, recent attempts suggest common overarching mechanisms to integrate the variety of functions assigned to rTPJ.

The nexus model (Carter and Huettel, 2013) tries to conciliate in a unified theory the role of rTPJ in mentalizing and attention, suggesting that TPJ is a "nexus" area where the overlap of lower-level functions (i.e., reorienting attention) leads to higher-order social-cognitive functions (i.e., mentalizing). The key idea of the nexus model is that TPJ would integrate information from different domains of cognition to construct a social context promoting decision-making.

A further overarching view is known as the circuit-breaking theory by Corbetta and colleagues $(2008 ; 2002)$. This theory hypothesizes that the reorientation of attention is the result of the coordinated action of the ventral and the dorsal attention network. Broadly speaking, rTPJ plays a critical role in the detection of unexpected but taskrelevant stimuli. As a node of the VAN, rTPJ would therefore act as a sort of circuit breaker for the dorsal attention network (DAN; Vossel et al., 2014). The activity of the latter, which is responsible for maintaining visuospatial information relevant for the current task-defined goals, would be interrupted by a signal of the VAN, with the consequence of reorienting the attention to a new salient stimulus. Noteworthy, this theory has been applied to social cognition as well, considering rTPJ as a relay to shift attention from an egocentric perspective to someone else's perspective, and vice versa (Corbetta et al., 2008).

An alternative explanation about the role of rTPJ in cognition is suggested by Geng and Vossel (2013), who refuse the core assumption of the circuit-breaking theory. The circuit-breaking theory posits that rTPJ triggers the reorienting of attention by interrupting the activity of the DAN. However, if it was true, this would entail that the activity of rTPJ occurs earlier than the activity of the brain regions of the DAN. On contrary, evidence from event-related potentials and transcranial magnetic stimulation (TMS) studies showed an opposite scenario: the frontal eye fields, which are part of the DAN, are activated earlier than rTPJ (i.e., the VAN) during attentional reorienting (Bardi et al., 2012; Thompson et al., 1996). Although Geng and Vossel (2013) agreed with the well-established role of TPJ in attentional control, they introduce an alternative explanation to reconcile the above-mentioned inconsistencies in an integrative view. Their theory originates from the functional meaning attributed to the P3 (also known as P300), an electrophysiological potential related to "contextual updating" (Polich, 2007). The P3 has been associated with the activity of several neural sources. The P3b, which is a particular subcomponent of P3, has been linked with TPJ and is considered to be a neurophysiological correlate of contextual updating (Polich, 2007; Verleger et al., 1994). In the contextual updating hypothesis, TPJ would update internal models of the environment/context with the aim to generate and drive adequate expectations and actions (Geng and Vossel, 2013). This theory is supported also by functional magnetic resonance imaging (fMRI) evidence showing the activation of TPJ in attentional tasks, in which the violation of expectations triggers the largest responses in this region (Vossel et al., 2006). Remarkably, the contextual updating hypothesis offers a model to interpret both low-level functions, for example reorienting 
attention, and high-level social functions, such as ToM, suggesting a common computational mechanism (i.e., contextual updating). From a social perspective, TPJ contributes to integrating the contextual representation of social situations needed to take the perspective of another person.

As the above-mentioned perspectives outline, clarifying the role of rTPJ in cognition has proven challenging because rTPJ is engaged across a broad range of processes. Taken together, both the perspectives attributing specific functions to rTPJ and the theories positing overarching mechanisms provide a fragmented view regarding the involvement of this region in cognition. This is going to make the translation of this knowledge into practical solutions very difficult. For example, current neuropsychological measures and clinical treatments mostly reflect this theoretical fragmentation as they focus on assessing and treating, separately, cognitive or functional domains (e.g., language, attention, ToM), hence assuming a modular view of brain functioning (Fotopoulou, 2014). The modular assumption, despite being historically central in cognitive science (Fodor et al., 1983), may not be the unique rationale underlying the creation of neuropsychological tests and clinical interventions. Although it is well-known that after brain damage cognitive functions may show dissociations of deficits (supporting a modular view of the mind; Shallice, 1988), it is noteworthy to underline that most of the time clinical patients show associations of deficits (other than dissociations; Corbetta et al., 2018, 2015). The importance of association of deficits has also been acknowledged in the field of neuropsychological rehabilitation, as typically deficits do not occur in isolation (Wilson et al., 2017). Consequently, the adoption of an alternative view, different from the "modularist" tradition, may stimulate a rethink of the rationale of clinical treatments and provide different expectations on the treatment outcomes (Brown and Kuperberg, 2015). One particular framework that can support this paradigm shift is predictive processing.

\subsection{Predictive processing framework for brain disease}

In the last decade, the concept of predictive processing has become popular in cognitive neuroscience because it outlines a unifying framework for understanding neural computation underlying perception, cognition, and action (Clark, 2013; Friston, 2012). Although several theories and concepts have been developed within the "predictive processing" umbrella term (e.g., predictive coding, Bayesian brain, or free energy principle), in this review we will refer to Andy Clark's general view (Clark, 2013). Clark offers an integrative perspective of these theories (Swanson, 2016) that postulates a core assumption: all individuals deal with environmental changes by predicting future events through the creation of internal models based on a spontaneous ability to distill causal structures in the world. The central idea of predictive processing is that an internal model identifies causal regularities from a complex variety of sensory signals, extracting what is significant and salient to predict 
future events. The mismatch between a prediction and the actual sensory input generates a prediction error. The goal of the "predictive brain" is to try to generate more and more accurate predictions and therefore to minimize the prediction error. This prediction error propagates up the processing hierarchy to update expectations and provide better predictions that are transferred down the hierarchy (Friston, 2019). Consequently, high-level beliefs are used to modulate low-level sensory predictions. Put simply, the brain is somehow a predictive machine that constantly generates, tests, and updates hypotheses. The degree of violation between ascending sensory information (bottom-up processes) and descending predictions (top-down processes) leads the system to respond either by integrating the new information, and therefore updating the internal model, or generating a new model.

Along with estimating predictions about future events, the brain also estimates the reliability of these predictions or, in other terms, their precision. Bayesian inference can be advocated to illustrate mathematically the concept of precision. Most of the time the causes of incoming sensory information are latent, simply unknown. Thus, the brain has to face an inverse problem, namely to estimate the causes of sensory information by generating inferences that result from both known information, so-called priors in Bayesian terms, and the incoming sensory information. The prediction resulting from priors and incoming sensory information is defined as the posterior probability that reflects the likelihood of the latent information being the cause of the sensory information.

Going back to the question of precision, it refers to the level of confidence in predictions, in other words, the estimation of their occurrence likelihood. As such, the predictive processing framework allows interpreting predictions as changes in the posterior probability that could be biased towards the prior or to the sensory evidence. For example, the posterior probability can be biased towards sensory evidence if the prior is unreliable (e.g., while performing a new task, such as the first time we drove a car). Conversely, posterior probability can be biased towards the prior by increasing the precision of the prior itself, hence generating a prediction that is not so different from one's original expectations (e.g., during the execution of an ordinary and repetitive task, such as driving through a well-known route). From a clinical perspective, it has been argued that neuropsychological deficits might be interpreted as the consequence of the overconfidence of predictions on priors or an underconfidence of sensory evidence. As one prominent example, in Parkinson's disease (PD), deficits in sensorimotor predictions result in an over-confidence in sensory evidence, causing inhibition of initiation and maintenance of voluntary actions (Wolpe et al., 2018). In other words, when either priors or sensory information are given more/less precision they should, predictions about our reality may become less accurate.

Predictive processing represents a revolution in cognitive neuroscience because, along with providing a global theory about how the brain works, encompassing also the cerebellum (Friston, 2010; Oldrati et al., 2021), it has laid the basis to interpret a variety of diseases as conditions deriving from aberrant predictive processing (Smith 
et al., 2021). From a theoretical point of view, any disruptions to a component of the model may cause a cascade of consequences leading to domain-general impairments. As suggested by Fotopoulou (2014), who interpreted anosognosia for hemiplegia as a deficit of predictive processing, several kinds of disruptions may impair the recursive dialectic between prior beliefs and current experience: (1) deficits to update predictions; (2) weak or absent prediction error signal; (3) firm adherence to predictions; (4) inability to optimize the precision of prediction errors; and, in general, (5) aberrant predictions.

Also Kocagoncu and colleagues (2021) suggested that aberrant predictive mechanisms may explain impairments of neurological patients. In general, difficulties resulting from disruptions at any level of predictive processing may affect both the cognitive and the motor domains. Concerning rTPJ, aberrant predictive processing resulting from real (e.g., traumatic brain lesion or strokes) or simulated (e.g., when TMS is applied to temporarily inactivate rTPJ) rTPJ lesions seem to affect high-order processes, such as awareness (Fotopoulou, 2014), self-agency (Ghajar and Ivry, 2008), moral judgment (Young et al., 2010), and action imitation (Era et al., 2020).

\section{3 rTPJ as a key node in predictive processing}

The hypothesis regarding the association between rTPJ and predictive processing is relatively recent but has been already supported by and discussed in several studies (Koster-Hale and Saxe, 2013; Park et al., 2021).

For example, recently Park and colleagues (2021) investigated a potential causal link between rTPJ and the updating of predictions. In their study, the authors used fMRI to investigate the dynamic process underlying the maintenance or updating of social impressions of others, as a function of the violation of expectations (i.e., the prediction error). They showed that the recruitment of rTPJ reflected the integration of prediction error signals: specifically, the engagement of rTPJ was related to the processing of the social prediction error and updating of prior beliefs. Similarly, corroborating the centrality of rTPJ in predictive processing, Mengotti and co-workers (2017) applied online TMS over rTPJ. In line with their hypothesis, TMS interfered with the participants' capability to update prior beliefs. In addition, the TMS disruption was determined only in precise timing, namely when the TMS pulse was delivered $300 \mathrm{~ms}$ after a target stimulus, not at $50 \mathrm{~ms}$. Of interest, the authors explained this result as further corroboration of the idea that rTPJ is one of the neural sources of the P3, an ERP component strictly associated with contextual updating (Geng and Vossel, 2013; Polich, 2007).

An interesting view has been suggested by Siman-Tov and co-workers (2019) who conducted a coordinate-based meta-analysis of neuroimaging studies engaging both prediction generation and violation. Their results showed a set of cortical and subcortical brain regions, including the inferior and middle frontal gyri, anterior insula, premotor cortex, pre-supplementary motor area, striatum, thalamus, cerebellum, as 
well as rTPJ. This assembly of structures would be engaged in higher-level predictions that have been proposed to belong to a putative "prediction network" subserving both perception and action. Interestingly, rTPJ is the only region within this prediction network that is also a crucial area of the VAN (Corbetta and Shulman, 2002). This concurrency has yielded the authors to suggest an intriguing role of rTPJ within the dynamics occurring between the VAN and the prediction network. Along with the wellestablished role of the VAN in the stimulus-driven changes in attentional focus, this network would be also activated in case of violation of expectations (Geng and Vossel, 2013), evidence that links the VAN to the predictive processing framework. Specifically, Siman-Tov and colleagues (2019) argued that the VAN might be part, together with other brain structures, of a larger network subserving domain-general high-order prediction. Pushing this idea further, the authors suggest that rTPJ, as a relevant hub of the VAN, has a key role in estimating the precision of priors and sensory evidence. This hypothesis is not new, since attention has been already interpreted through the lens of predictive processing (Feldman and Friston, 2010; Hohwy, 2013). However, this scenario provides a sharpened interpretation of neural correlates of mechanisms responsible for predictions.

To sum up, a consistent number of studies outline a view in which rTPJ seems to be a fundamental cortical region subserving predictive processing and possibly related to a core set of areas identified as a "prediction network". As we have seen before, rTPJ is certainly a crucial structure of the "predictive brain". However, advancing the hypothesis that direct damage or disconnection of this area is a necessary condition to disrupt the prediction network and, consequently, cause deficits ascribable to aberrant predictive processing would be, at the moment, merely speculative. Instead, neurological disorders affecting rTPJ may be a sufficient, even if not necessary, condition to cause difficulties related to predictive processes, leading to a plethora of impairments as overconfidence of prior beliefs or underconfidence in sensory information, alongside a difficulty to detect errors, and a general inability to distill probabilistic structures in the world. Of course, predictive processing deficits can also emerge as a consequence of the impairment of other brain regions, in line with SimanTov and colleagues (2019) who suggest that rTPJ is only part of an extended network subserving high-level predictions.

The aim of this study is to provide a state-of-the-art overview of structural and functional aberrant outcomes following rTPJ "disconnection" from a putative prediction network, suggesting the involvement of rTPJ in a network potentially responsible for prediction. 


\section{Methods}

The current systematic review is reported according to the recently updated guidelines of Preferred Reporting Items for Systematic reviews and Meta-Analyses (PRISMA, Page et al., 2021).

\subsection{Search}

A systematic literature search was performed on three databases: PubMed, Psyclnfo, and Embase. The search terms included the conjunction of the following terms: (("right" AND ("TPJ" OR "temporo parietal junction" OR "temporoparietal junction" OR "temporo-parietal junction" OR "temporo-parietal region")) OR "rTPJ") AND ("lesion"” OR "neurological" OR "Huntington" OR "mild cognitive impairment" OR "Parkinson disease" OR "multiple sclerosis" OR "stroke" OR "brain damage" OR "dementia" OR "Alzheimer" (all keywords) OR "stroke" OR "multiple sclerosis" OR "dementia" (all Mesh terms)). For details about the full search strategy for all databases please see the Supplementary Materials. Additional records relevant to the topic of the systematic search (e.g., articles that were cited by other articles) were also included.

No restriction on publication date range was applied (last date of search: 23rd October 2020) and only studies with an English version and published in peer-reviewed journals were considered.

Inclusion criteria were established a priori and were the following: i) peer-reviewed papers; ii) papers written in English; iii) papers including adult ( $>18$ years) neurological patients; iv) papers studying the functional role of rTPJ (both due to a direct lesion of rTPJ or to its disconnection from other structures).

Exclusion criteria were also established a priori and were the following: i) papers without data analysis; ii) reviews, meta-analysis, methodological papers; iii) papers found incidentally by the algorithm, but not including rTPJ; iv) papers involving animal models, children ( $<18$ years), healthy older adults only, non-neurological patients.

\subsection{Risk of bias}

To reduce the risk of bias, two independent reviewers (F.M. and S.L.) screened the articles and decided for appropriateness. Discrepancies in the evaluation of an article were resolved by a third author (R.P.). To assess the quality of the studies included, we applied the Newcastle-Ottawa Scale (NOS), a tool developed to evaluate nonrandomized studies for systematic reviews (Wells et al., 2011); more specifically, we used a version adapted for cross-sectional studies (Patra et al., 2015) and we customized it according to the aims of our systematic search (please, see Table S1 and S2, in the Supplementary Materials, for details on NOS). 


\subsection{Data extraction}

Data extraction was performed by F.M., R.P., and S.L. Each author was assigned a subset of papers to review. For each study, we highlighted the aim of the study, whether it focused on a cognitive domain and, if so, which specific domain was investigated, differentiating between a priori interests or incidental findings. This information was included to pinpoint potential selective biases of rTPJ studies towards certain cognitive functions. Data extracted from each subset of papers was subsequently and independently double-checked also by the authors that did not perform data extraction on that specific subset.

\section{Results}

The systematic literature search provided a total of 539 articles, as shown in the PRISMA flow diagram (Figure 1). After discarding duplicates, a total of 199 records remained. These articles were screened based on title and abstract, according to the established criteria; 119 articles were considered not appropriate; thus, the full text of 81 articles was screened. A final set of 54 articles were judged suitable to be included in the review as the remaining 27 papers did not meet the inclusion criteria.

\section{[Figure 1]}

The 54 identified studies were clustered into the following 4 subgroups according to the pathology of interest: i) "acquired brain injury" (which included right non-traumatic damage, bilateral non-traumatic damage, and traumatic brain injury); ii) "neurodegenerative disease" (including Alzheimer, Mild Cognitive Impairment, Frontotemporal Dementia, Dementia with Lewy Bodies, PD); iii) "white matter disease" (which included multiple sclerosis and hyperintense lesions); iv) several pathologies that have been grouped as "other pathologies" as they referred to a minority of studies found (epilepsy, psychogenic nonepileptic seizures, migraine, and hemianopia). Importantly, we included both studies where the lesion involved focal damage to rTPJ and studies where rTPJ was not directly damaged but the lesion caused a disconnection between rTPJ and other brain areas/networks. In this latter case, the functional damage was interpreted by the authors as a consequence of the segregation of rTPJ from other areas/networks.

A summary of the main results for each subgroup can be found in Table 1. In each of the following sections, we present a synthesis of the main results for each subgroup. 


\subsection{Acquired brain injury}

Acquired brain injury is an umbrella term encompassing a wide spectrum of brain lesions that are not hereditary, congenital, or degenerative, and are characterized by a traumatic/non-traumatic etiology. Acquired brain injury can result in impairments in cognition, motor function, sensory processing, and emotional disturbances. Studies on patients with acquired brain injury can help investigate how rTPJ damage affects cognitive functioning. In the present review, 29 studies have been included within this subgroup: 22 studies regarding right non-traumatic brain lesions, 6 studies with bilateral non-traumatic brain damage, and 1 study with patients with traumatic brain injury (TBI). Sixteen out of 29 studies specifically mentioned patients with hemispatial neglect, and their results have been summarized at the end of this section.

Several authors suggest that cognitive and motor impairments observed in patients could result both from direct damage of rTPJ and from a disconnection of this brain structure from other areas or networks. This latter scenario implies that rTPJ can be directly damaged or not. For example, the disconnection of rTPJ from the frontoparietal network could be responsible for a detrimental effect in orienting attention to relevant events (Pedrazzini and Ptak, 2019), anosognosia for hemiplegia (Monai et al., 2020), and a selective impairment at the expense of cognitive flexibility (i.e., executive functions), specifically in set-shifting abilities (Mandonnet et al., 2017). Interestingly, Wawrzyniak and colleagues (2018) linked the patients' deficits to a breakdown of networks of the right hemisphere. Through the lesion network-symptommapping approach, the authors investigated the phenomenon of the rubber hand illusion in patients with mild to moderate stroke symptoms and demonstrated the engagement of rTPJ in eliciting the illusory body-ownership feeling. A similar result was found by Martinaud and co-workers (2017) who showed that lesions associated with disturbing sensations of limb ownership included rTPJ, supramarginal gyrus, and middle frontal gyrus. Thus, rTPJ, together with other brain regions, seems to support the integration of body sensations to achieve a global body representation (Boccia et al., 2020).

Studies included in the next subsection found an association between rTPJ and attention impairment, without advocating a disconnection of this area with other circuits but interpreting deficits as the consequence of rTPJ damage itself. For example, Shomstein and colleagues (2010) studied the neural bases of top-down (goal-directed) and bottom-up (stimulus-driven) attentional orienting. Starting from previous evidence showing the involvement of the superior parietal lobule for top-down attentional orienting and rTPJ for bottom-up attentional orienting, they selected a group of patients with lesions in these regions of interest. A lesion overlap analysis showed a double dissociation: (1) impairment of top-down attentional orienting, but normal bottom-up orienting, was related to superior parietal lobule lesions; (2) impairment of bottom-up attentional orienting, but normal top-down orienting, was related to TPJ lesions. 
Together with attentional orienting, rTPJ seems to play a role also in temporal attention. Agosta and co-workers (2017) investigated the capability to perceive the sequential order of two events, asking participants to perform temporal judgment tasks. To this aim, they conducted two experiments on a group of patients with left and right parietal lesions. Results of the first experiment showed reduced visual temporal processing in patients with right parietal damage, while patients with lesions in the opposite hemisphere performed normally. The second experiment confirmed the role of the right parietal brain regions in temporal judgments. In particular, repetitive TMS over rTPJ - but not the left TPJ - bilaterally disrupted the ability of participants to visually discriminate stimuli across time.

Along with attention, rTPJ has been found to be implicated in a variety of other functions. For instance, Starkstein and colleagues (1992) investigated the neural correlates of anosognosia, showing that patients with mild or severe anosognosia more often had temporoparietal lesions (among several other lesions), as compared to patients with no or moderate anosognosia. As for the relation of rTPJ with mental state attribution, in Leigh and colleagues (2013) patients with right acute stroke were recruited to investigate whether deficits in affective empathy were related to lesion site alone, or also affected by other aspects, specifically lesion volume, age of patients, neglect, and prosody comprehension. What the authors found, confirming previous evidence, is that a unilateral lesion of rTPJ is not sufficient to impair affective empathy. Similarly, Cohen-Zimerman and colleagues (2021) employed voxel-based lesionsymptom mapping to examine the relationship between focal brain lesions and mental state attribution. They tested a large sample of patients selected from the Vietnam Head Injury Study. In line with Leigh's group (2013), Cohen-Zimerman and co-workers (2021) did not reveal the involvement of rTPJ in mental state attribution. Thus, both these studies suggest that rTPJ could not be necessary for mental state attribution.

Finally, rTPJ was also associated with motor functions. Indeed, several studies revealed the role of this brain region in motor planning and sensorimotor integration. Singh and Knight (1993) aimed to identify a relation between movement-related potentials, measured in a self-paced button-press task, and unilateral lesions in the posterior association cortex. Results from this study revealed an involvement of the posterior association cortex damage in reducing the movement-related potential amplitudes. This result established the role of the superior parietal regions (and rTPJ) in movement preparation. Kaski and colleagues (2016) studied the neural underpinnings of vestibular-spatial perception asking patients with right damage to perform a series of vestibular reorientation tasks in the dark. This study showed that the brain encodes self-motion and spatial perception separately and rTPJ seems selectively crucial in spatial perception. The authors suggested that this area may work as a mental temporal integrator somehow, in which the subjective estimation of motion velocity over time is integrated with the updating of traveled distance perception in the dark (i.e., under vestibular guidance). 
As previously mentioned, in the section related to acquired brain injury, 16 papers explicitly considered hemispatial neglect. Lesion analysis confirmed that rTPJ is associated with the occurrence of spatial neglect (Demeurisse et al., 1997; Ptak and Schnider, 2011). Crucially, rTPJ contributed to predicting the patients' performance in a variety of visuospatial tasks (Toba et al., 2020). For example, Kaufman and colleagues (2009) found that line bisection deficits in patients with neglect were associated with damage to the anterior part of rTPJ, among other temporal regions. In addition to gray matter damage, Golay and her team (2008) highlighted that patients who showed large bisection bias and small cancellation errors also had white matter damage located in the proximity of rTPJ. Similarly, Thiebaut de Schotten and coworkers (2014) investigated the role of white matter disconnection in chronic spatial neglect measured with line bisection and letter cancellation. Results of their study revealed that white matter lesions in ITPJ, among other frontoparietal areas, predicted whether a patient showed neglect symptoms and had a worse bisection performance. Pedrazzini and colleagues (2017) enrolled neglect patients with right-hemispheric lesions to examine which sites were more strongly associated with visuospatial processing of single objects or space. They observed that damage to rTPJ was a strong predictor of space-based variables only, suggesting that space and objectbased processing have distinct neural bases and that space-based processing is grounded in rTPJ. Additional typical manifestations of neglect encompass the phenomenon of visual extinction, which is the inability of brain-damaged patients to detect a contralesional target in the presence of a competing ipsilesional stimulus. In a study by Karnath and his team (2003), the authors classified patients into three groups according to their symptoms: pure extinction (no neglect), extinction plus neglect, pure neglect (no extinction). Results showed that patients with extinction and neglect had lesions comparable to that of pure extinction patients, namely at the level of rTPJ, covering also other temporoparietal areas. Instead, extinction plus neglect patients reported greater damage of rTPJ compared to those with extinction only. Also, Ticini and colleagues (2010) focused on visual extinction, conducting normalized perfusion-weighted MRI analysis. Findings indicated that patients with visual extinction showed cortical malperfusion around rTPJ. Altogether, these findings lend support to the hypothesis that rTPJ is essential for the bottom-up detection of stimuli.

Together with visuospatial processing, it has been found that rTPJ is implicated in a variety of other functions. Among these, Chechlacz and colleagues (2014) showed that areas typically associated with neglect may support visuospatial memory performance. In a recent study, Dressing and co-workers (2020) investigated the relationship between neglect and apraxia (an impairment in tool use or imitation of gestures, naturalistic actions, and meaningless postures) in patients with right hemisphere damage. Interestingly, voxel-based lesion-symptom mapping revealed a negative correlation between apraxia and rTPJ integrity. Others investigated the anatomical substrates of neglect dyslexia showing the pivotal contribution of rTPJ in reading (Lee et al., 2009). Finally, Rousseaux and colleagues (2015) examined the neural correlates of behavioral manifestations of neglect in daily activities. Findings 
revealed that difficulties in daily living mainly resulted from subcortical white matter lesions underlying rTPJ, among other temporoparietal areas.

A separate mention should be made for all those studies that have investigated how rTPJ disconnection from other areas or networks can yield different consequences. Hattori and colleagues (2018), for example, showed that in patients with rTPJ lesions the VAN was damaged. Lesions included the white matter connecting rTPJ and surrounding areas with frontal regions. Moreover, in those patients with infarction in the territory of the posterior cerebral artery, white matter tracts connecting the thalamus to rTPJ and the surrounding areas were damaged. The authors argued that different lesion patterns may underlie different neglect phenotypes. Specifically, damage to the VAN impairs stimulus-driven, bottom-up attentional reorienting from current focus to new and unexpected focus by modulating the DAN. Instead, damage in the thalamus and related white matter tracts may secondarily impair the spatial attention-related cortices due to interrupted somatosensory and feedback information from the thalamus. In another study, Committeri and colleagues (2015) tested patients for representational neglect, visual extrapersonal/perceptual neglect, and personal neglect. Results showed that only rTPJ emerged as significantly more involved in the genesis of representational neglect for places. In particular, the posterior rTPJ appeared uniquely connected with the DMN. Finally, Pedrazzini and Ptak (2020) investigated the neural bases of spatial awareness, which is particularly impaired in neglect. Results showed that damage at the supramarginal part of rTPJ, together with frontoparietal connections, was the best predictor of neglect.

To summarize, regarding the functional alteration investigated by each study, acquired rTPJ damage was associated with impairment of attention, awareness, executive functions, visuospatial memory, spatial perception, movement preparation, and difficulties in activities of daily living (see Table 1). These deficits have been interpreted in two ways: locally or globally. The local explanation considers the functional impairment as a direct consequence of the rTPJ lesion. Instead, the global explanation outlines a more complex scenario where the rTPJ damage, together with the alteration to other brain structures, is the cause of the functional impairment.

\subsection{Neurodegenerative diseases}

Neurodegenerative diseases are a group of disorders characterized by the progressive degeneration of nerve cells, in the central or the peripheral neural system (Palop et al., 2006). Fifteen studies were included in this subgroup, 13 studies comprise patients with various types of dementia or cognitive impairment, including Alzheimer's Disease (AD), frontotemporal dementia (FTD), mild cognitive impairment $(\mathrm{MCl})$, functional neurological disorder, corticobasal syndrome, dementia with Lewy bodies (DLB). Two out of 15 were conducted on patients with PD. 
Among the studies that investigated the relationship between rTPJ and attention in AD patients, the one by Sorg and his team (2012) found that direction and degree of spatial attention bias correlated with TPJ activity. Furthermore, Yamashita and colleagues (2019) showed that the connectivity between rTPJ and posterior parietal cortex was diminished in poor performers during a task on orientation for time. In another study, Luks and colleagues (2010) recruited a heterogeneous group of patients with several neurodegenerative disorders. Results showed that the atrophy in the TPJ-ventrolateral prefrontal cortex (VLPFC) network was associated with slower attentional control on accurate trials. This network (i.e., TPJ-VLPFC) is thought to be responsible for reorienting attention towards salient and infrequent stimuli, in a bottomup fashion. In the absence of an efficient top-down attentional control system mediated by the DLPFC-ACC network, accurate and speedy processing of incongruent Flanker task stimuli may be accomplished by the bottom-up reorienting and inhibitory mechanisms of the TPJ-VLPFC network.

A limited number of studies also focused on aspects related to self-awareness, such as Pickut and colleagues (2013) who found increased gray matter density in a variety of regions, including bilateral TPJ, in a group of PD patients who followed an 8-week mindfulness-based intervention compared to a standard training. Concerning selfawareness, Zamboni and co-workers (2010) found that in patients with various forms of FTD, the degree of anosognosia for behavioral impairment (which is a condition in which patients are often partially, if not completely, unaware of the behavioral deficits) correlated with gray matter atrophy in the posterior regions of the brain, near rTPJ region, suggesting a role for rTPJ in anosognosia and general self-awareness. Also, Baez and her team (2019) tested patients with behavioral variant FTD (bvFTD) and patients with bipolar disorder, which present overlapping symptoms with the neurodegenerative disorder in the domain of cognitive and social functioning. BvFTD patients, who also showed greater executive functions and theory of mind deficits than psychiatric patients, had atrophy of several regions, including rTPJ. The authors suggested that rTPJ is intended as part of the extended cortical-limbic networks, which play a role in social cognition. As for memory deficits, Kang and colleagues (2019) investigated the effects of $A D$ and DLB on cognition and brain atrophy, and they found that $A D$ was associated with prominent memory deficits and brain atrophy in the medial temporal lobe and temporoparietal association cortices, while DLB was characterized by visuospatial, attention, and executive dysfunction.

The majority of studies found an impairment of rTPJ while investigating the structural and functional integrity of the brain, without a priori focus on a specific cognitive domain. Qian and colleagues (2015) investigated the functional and structural substrates of attention by testing the integrity of the VAN and DAN networks. Their data showed decreased functional connectivity in the orbital ventral frontal cortex and TPJ region in AD patients, whereas functional connectivity was preserved in amnestic $\mathrm{MCl}$ compared with controls. In addition, gray matter density in the right ventral frontal cortex was correlated with functional deterioration in rTPJ and ventral frontal cortex in 
AD. Recently, De Marco and colleagues (2019) used structural MRI data of AD, MCI patients, and controls to disentangle DMN patterns that are associated with normal aging or neurodegeneration. They found a significant positive association between hippocampal volumes and the DMN connectivity in rTPJ. The authors suggested that rTPJ may subserve ToM processes and social cognition through its connection to the DMN. They also found an association between rTPJ and verbal episodic memory. Diez and co-workers (2019) observed that altered connectivity in rTPJ (as part of the multimodal integration network) and insular regions correlated with neurological symptoms, including altered interoception and self/emotional awareness. These results suggested that the functional alteration in insula and rTPJ play a crucial role in promoting altered awareness in functional neurological disorders. In addition, the study of Zou and colleagues (2014) revealed a decrease in cerebral blood flow values in $A D$ patients compared to controls in bilateral frontal regions, the temporal lobe, bilateral TPJ, as well as parietal and hippocampal regions. In a longitudinal investigation, a significant correlation between the worsening of depression and the lowering of the cortical thickness in rTPJ over time (after approximatively 18 months) was observed in non-demented PD patients (Hanganu et al., 2017). Three studies investigated the role of apathy in patients with neurodegenerative disorders, finding structural or functional implications of rTPJ. Along this line, Blanc and colleagues (2015) investigated cortical thickness in a variety of patients with neurodegeneration. In the patients with DLB, the cortical thinning was found predominantly in rTPJ, insula, and other cortices, as compared to controls. In another study, Rohrer and his team (2012) examined patients with primary progressive aphasia with AD or the presence of cerebrospinal fluids compatible with $A D$, showing a pattern of cortical thinning in many regions when patients were compared to controls. In those patients with more severe diseases, they found increased involvement of the left anterior temporal and frontal cortices, posterior cingulate, medial temporal lobe, and rTPJ. Another study had a similar aim, namely to investigate the cortical changes in association with apathy (Eslinger et al., 2012). They showed that apathy was significantly correlated with atrophic changes in several regions, including rTPJ in patients with bvFTD, compared to other forms of dementia. Behaviorally, multiple measures of executive function and social cognition were impaired in the bvFTD sample.

To sum up, this paragraph shows how the involvement of rTPJ in neurodegenerative disorders is associated with a variety of impairments. Functionally, deficits associated with rTPJ consisted of impairment of attention, social cognition, executive functions, awareness (anosognosia), memory, and language. In addition, several studies showed the relationship between rTPJ, mood, and apathy (see Table 1). 


\subsection{White matter disease}

In this paragraph, we discuss studies on a group of heterogeneous disorders that engage degeneration of the white matter of the brain, that could disrupt cognitive functioning or result in other symptoms. Studies on patients with white matter disruptions can help investigate whether and how structural disconnections also impact rTPJ functioning. Five studies have been included in this subgroup, 4 studies with patients with multiple sclerosis (MS), and 1 study on patients with white matter hyperintense lesions.

In a first study, Carotenuto and colleagues (2018) tested MS patients, who showed a correlation between rTPJ and deficits in pragmatic and communicative abilities (tested with the Assessment of Pragmatic Abilities and Cognitive Substrates - APACS - test, Arcara and Bambini, 2016). Here, a direct correlation between the APACS score and a cluster within the paracingulate cortex was found when evaluating the right Geschwind's area (encompassing rTPJ), thus showing a relation between this area and pragmatics abilities. Huang and co-workers (2019) tested patients with relapsingremitting MS that showed decreased dynamic functional connectivity within both the DAN and VAN, of which rTPJ is part of, but increased connectivity between the two networks; they also found that the connectivity between rTPJ and right ventral frontal cortex was negatively correlated with the total white matter lesion loads, suggesting that the detected effects of transient connectivity pattern are relevant to the lesions damage (Huang et al., 2019). Kim and colleagues (2019) tested resting-state connectivity in MS patients using magnetoencephalography. They reported an increase in alpha-band neural power in rTPJ, particularly in a subgroup of patients who experienced mixed neuropathic pain; the authors suggested that this effect may reflect an overactivity of rTPJ for overflowing sensory information. In another study, altered connectivity of rTPJ with the DMN was found in a subgroup of MS patients with mixedneuropathic pain (Bosma et al., 2018). This result was interpreted as the index of an altered engagement of the ascending nociceptive and descending modulation pathway. Peng and colleagues (2016) quantified with voxel-based morphometry the gray matter density and correlated it with the white matter hyperintense load, this latter visually estimated by two expert neurologists. The authors found that patients with white matter hyperintense lesions had a greater increase of gray matter density in rTPJ. They also found a negative correlation between rTPJ and white matter lesion load (Peng et al., 2016).

\subsection{Other pathologies}

Five papers studied the involvement of rTPJ in pathologies not included in the previous sections (see Table 1). 
The first two studies focused on epileptic patients. Beauchamp and colleagues (2012) investigated the perception of phosphenes following electrical stimulation of the visual cortex, in patients with subdural electrodes for surgical treatment of epilepsy. Electrodes in the visual cortex provided the stimulation, whereas the non-stimulating electrodes implanted in other sites of the brain were used for recording. Results showed that a much greater response of gamma oscillations $(60-150 \mathrm{~Hz})$ was observed in TPJ and close areas during electrical stimulation of the visual cortex, particularly when phosphenes were perceived. Jiang and colleagues (2018) aimed at assessing the functional and causal connectivity patterns of the attention networks and DMN in patients with refractory epilepsy, using fMRI. All patients showed a decreased activation within the VAN in the bilateral TPJ and prefrontal cortex and the interaction between the attention networks (VAN, DAN) and DMN was altered, as compared to controls.

One of the remaining four studies considered psychogenic non-epileptic seizures. Peterson and co-workers (2018) stimulated a small group of patients with psychogenic non-epileptic seizures with repetitive TMS over rTPJ, finding a decrease in weekly seizure rates after treatment. Improvement was also associated with lower measures of dissociation (particularly, conversion disorder).

One study focused on the administration of transcutaneous auricular vagus nerve stimulation (taVNS) in migraine patients (Zhang et al., 2019). Results showed that functional connectivity in rTPJ and other sites (hippocampal, temporal, parietal, and pontine regions) significantly increased following real compared to sham stimulation. Other significant results included increases in resting-state connectivity between rTPJ and locus coeruleus, and between rTPJ and left secondary somatosensory cortex. Such increases were negatively associated with the frequency of migraine attacks during the preceding month.

Finally, Lu and colleagues (2018) tested chronic hemianopic patients during a visual rehabilitation training. Besides improvements in their contrast sensitivity (no behavioral attention tests were administered), functional connectivity results show increased activation in rTPJ after training and strengthening of connectivity between cingulate and insular regions to rTPJ (as part of the attention network). 
Table 1. A summary of the studies included in the systematic review.

\begin{tabular}{|c|c|c|c|c|c|c|c|c|c|c|c|c|c|c|}
\hline Authors & Year & Damage & Pathology & Participants & $\begin{array}{l}\text { Neuroimaging } \\
\text { method }\end{array}$ & Attention & $\begin{array}{l}\text { Awareness } \\
\text { and social } \\
\text { cognition }\end{array}$ & Language & $\begin{array}{l}\text { Executive } \\
\text { functions }\end{array}$ & Memory & $\begin{array}{l}\text { Other } \\
\text { domains }\end{array}$ & $\begin{array}{l}\text { Behavioral } \\
\text { measurements }\end{array}$ & $\begin{array}{l}\text { Neuroimaging } \\
\text { measurements }\end{array}$ & Findings (related to the rTPJ) \\
\hline $\begin{array}{l}\text { Agosta et } \\
\text { al., }\end{array}$ & 2017 & $\begin{array}{l}\text { Bilateral } \\
\text { damage }\end{array}$ & $\begin{array}{l}\text { Acquired } \\
\text { brain injury }\end{array}$ & $\begin{array}{l}\text { Experiment 1: } 18 \\
\text { RD, } 5 \text { LD, } 18 \\
\text { HC; } \\
\text { Experiment 2: } 10 \\
\text { HC }\end{array}$ & MRI and NIBS & $\begin{array}{l}\text { AIM } \\
\text { temporal } \\
\text { attention }\end{array}$ & & - & & & & $\begin{array}{l}\text { Computerized task: } \\
\text { simultaneity } \\
\text { judgment task }\end{array}$ & $\begin{array}{l}\text { Repetitive transcranial } \\
\text { magnetic stimulation }\end{array}$ & $\begin{array}{l}\text { Results from the first experiment showed reduced visual } \\
\text { temporal processing in patients with the right parietal } \\
\text { damage, instead of patients with damage in the opposite } \\
\text { hemisphere that performed normally. The second } \\
\text { experiment confirmed the role of the right parietal brain } \\
\text { regions in temporal judgments. In particular, repetitive } \\
\text { TMS over the rTP - but not homologous one - bilaterally } \\
\text { disrupted the ability of participants to visually discriminate } \\
\text { stimuli across time }\end{array}$ \\
\hline $\begin{array}{l}\text { Boccia et } \\
\text { al., }\end{array}$ & 2020 & $\begin{array}{l}\text { Right } \\
\text { damage }\end{array}$ & $\begin{array}{l}\text { Acquired } \\
\text { brain injury }\end{array}$ & $26 \mathrm{RD}, 39 \mathrm{HC}$ & MRI & - & $\begin{array}{l}\text { AlM body } \\
\text { structural } \\
\text { representati } \\
\text { on }\end{array}$ & - & - & - & - & $\begin{array}{l}\text { Computerized } \\
\text { battery of tasks } \\
\text { developed by the } \\
\text { group to test body } \\
\text { representations }\end{array}$ & $\begin{array}{l}\text { Voxel-based lesion- } \\
\text { symptom mapping }\end{array}$ & $\begin{array}{l}\text { The rTPJ, together with other areas, may be crucial in the } \\
\text { integration of body sensations to achieve a global body } \\
\text { representation }\end{array}$ \\
\hline $\begin{array}{l}\text { Cohen- } \\
\text { Zimerman } \\
\text { et al., }\end{array}$ & 2020 & $\begin{array}{l}\text { Traumati } \\
\text { c brain } \\
\text { injury }\end{array}$ & $\begin{array}{l}\text { Acquired } \\
\text { brain injury }\end{array}$ & $\begin{array}{l}16 \text { rTPJ, } 7 \text { ITPJ, } \\
30 \text { rDLPFC, 28 } \\
\text { IDLPFC, } 34 \text { with } \\
\text { no lesion in the } \\
\text { PFC or the TPJ } \\
\text { bilaterally, } 30 \mathrm{HC}\end{array}$ & MRI & & $\begin{array}{l}\text { AlM theory } \\
\text { of mind }\end{array}$ & - & & & & $\begin{array}{l}\text { The strange stories } \\
\text { test }\end{array}$ & $\begin{array}{l}\text { Voxel-based lesion- } \\
\text { symptom mapping }\end{array}$ & The rTPJ was not involved in mental state attribution \\
\hline $\begin{array}{l}\text { Kaski et } \\
\text { al., }\end{array}$ & 2016 & $\begin{array}{l}\text { Right } \\
\text { damage }\end{array}$ & $\begin{array}{l}\text { Acquired } \\
\text { brain injury }\end{array}$ & $\begin{array}{l}18 \mathrm{RD}, 2 \\
\text { avestibular } \\
\text { patients, } 14 \mathrm{HC}\end{array}$ & MRI & - & - & - & - & - & $\begin{array}{l}\text { AlM } \\
\text { vestibula } \\
r \text {-spatial } \\
\text { perceptio } \\
\text { n, } \\
\text { travelled } \\
\text { distance, } \\
\text { motion } \\
\text { duration }\end{array}$ & $\begin{array}{l}\text { Subjective angular } \\
\text { position, velocity, } \\
\text { and motion duration } \\
\text { during whole-body } \\
\text { angular rotations in } \\
\text { the dark }\end{array}$ & $\begin{array}{l}\text { Voxel-based lesion- } \\
\text { symptom mapping }\end{array}$ & $\begin{array}{l}\text { Patients with rTPJ damage showed impaired spatial } \\
\text { orientation performance. This group of patients } \\
\text { underestimated both the travelled distance and the motion } \\
\text { duration during a task performed in the dark }\end{array}$ \\
\hline $\begin{array}{l}\text { Leigh et } \\
\text { al., }\end{array}$ & 2013 & $\begin{array}{l}\text { Right } \\
\text { damage }\end{array}$ & $\begin{array}{l}\text { Acquired } \\
\text { brain injury }\end{array}$ & $28 \mathrm{RD}, 24 \mathrm{HC}$ & MRI & - & $\begin{array}{l}\text { AlM } \\
\text { affective } \\
\text { empathy }\end{array}$ & - & - & - & - & $\begin{array}{l}\text { Affective and } \\
\text { cognitive empathy } \\
\text { measured with } \\
\text { several tasks: the } \\
\text { Affective Empathy } \\
\text { Task (stories), the } \\
\text { Interpersonal } \\
\text { Reactivity Index, } \\
\text { the Aprosodia } \\
\text { Battery }\end{array}$ & $\begin{array}{l}\text { Diffusion weighted } \\
\text { image }\end{array}$ & $\begin{array}{l}\text { A unilateral lesion of the rTPJ is not sufficient to impair } \\
\text { affective empathy }\end{array}$ \\
\hline $\begin{array}{l}\text { Mandonn } \\
\text { et et al., }\end{array}$ & 2017 & $\begin{array}{l}\text { Right } \\
\text { damage }\end{array}$ & $\begin{array}{l}\text { Acquired } \\
\text { brain injury }\end{array}$ & Single case & fMRI & & & & $\begin{array}{l}\text { AlM set- } \\
\text { shifting } \\
\text { abilities }\end{array}$ & & & $\begin{array}{l}\text { Several tasks to } \\
\text { explore: language } \\
\text { functions, praxis, } \\
\text { non-verbal } \\
\text { semantic } \\
\text { association, } \\
\text { calculus, memory, } \\
\text { attention, spatial } \\
\text { awareness, } \\
\text { executive functions }\end{array}$ & $\begin{array}{l}\text { Resting state fronto- } \\
\text { parieto-temporal } \\
\text { networks extracted by } \\
\text { means of ICA }\end{array}$ & $\begin{array}{l}\text { The surgical disconnection of the rTPJ from the fronto- } \\
\text { temporo-parietal network led to a selective impairment of } \\
\text { cognitive flexibility, in particular the deterioration in set- } \\
\text { shifting abilitites }\end{array}$ \\
\hline
\end{tabular}




\begin{tabular}{|c|c|c|c|c|c|c|c|c|c|c|c|c|c|c|}
\hline $\begin{array}{l}\text { Martinaud } \\
\text { et al., }\end{array}$ & 2017 & $\begin{array}{l}\text { Right } \\
\text { damage }\end{array}$ & $\begin{array}{l}\text { Acquired } \\
\text { brain injury }\end{array}$ & $31 \mathrm{RD}$ & MRI & - & $\begin{array}{l}\text { AlM body } \\
\text { perception }\end{array}$ & - & - & - & - & $\begin{array}{l}\text { A modified version } \\
\text { of the Cutting } \\
\text { questionnaire } \\
\text { (Cutting, 1978) }\end{array}$ & $\begin{array}{l}\text { Voxel-based lesion- } \\
\text { symptom mapping }\end{array}$ & $\begin{array}{l}\text { Damage associated with disturbed sensation of limb } \\
\text { ownership included, among several areas, the rTPJ }\end{array}$ \\
\hline $\begin{array}{l}\text { Monai et } \\
\text { al., }\end{array}$ & 2020 & $\begin{array}{l}\text { Bilateral } \\
\text { damage }\end{array}$ & $\begin{array}{l}\text { Acquired } \\
\text { brain injury }\end{array}$ & $\begin{array}{l}35 \text { hemiplegia, } \\
28 \text { anosognosia } \\
\text { for hemiplegia }\end{array}$ & MRI & - & $\begin{array}{l}\text { AlM } \\
\text { anosognosi } \\
\text { a for } \\
\text { hemiplegia }\end{array}$ & - & - & - & - & - & Disconnectome maps & $\begin{array}{l}\text { The disconnection between the inferior frontal gyrus with } \\
\text { the TPJ may be critical in anosognosia for hemiplegia } \\
\text { because this latter seems to integrate multimodal signals } \\
\text { (body and visuospatial signals) and switch from inner to } \\
\text { external perspectives }\end{array}$ \\
\hline $\begin{array}{l}\text { Pedrazzin } \\
\text { i and } \\
\text { Ptak, }\end{array}$ & 2019 & $\begin{array}{l}\text { Right } \\
\text { damage }\end{array}$ & $\begin{array}{l}\text { Acquired } \\
\text { brain injury }\end{array}$ & $\begin{array}{l}10 \text { rTPJ, } 9 \\
\text { IPFC/insula, } 10 \\
\text { subcortical } \\
\text { damage, } 12 \text { HC }\end{array}$ & MRI & $\begin{array}{l}\text { AlM } \\
\text { orienting } \\
\text { attention }\end{array}$ & - & - & - & - & - & $\begin{array}{l}\text { Computerized task: } \\
\text { spatial cueing task }\end{array}$ & $\begin{array}{l}\text { Voxel-based lesion- } \\
\text { symptom mapping }\end{array}$ & $\begin{array}{l}\text { Patients with TPJ damage, but not the group with lateral } \\
\text { prefrontal cortex/insula damage, exhibited exaggerated } \\
\text { attention to behaviorally relevant cues }\end{array}$ \\
\hline $\begin{array}{l}\text { Shomstei } \\
\text { n et al., }\end{array}$ & 2010 & $\begin{array}{l}\text { Right } \\
\text { damage }\end{array}$ & $\begin{array}{l}\text { Acquired } \\
\text { brain injury }\end{array}$ & $9 \mathrm{RD}, 9 \mathrm{HC}$ & MRI & $\begin{array}{l}\text { AIM } \\
\text { attentional } \\
\text { orienting }\end{array}$ & - & - & - & - & - & $\begin{array}{l}\text { To examine the } \\
\text { integrity of top- } \\
\text { down attentional } \\
\text { orienting: a variant } \\
\text { of the Sperling and } \\
\text { Reeves (1980) } \\
\text { task. To examine } \\
\text { the bottom-up } \\
\text { attentional orienting } \\
\text { abilities: a variant of } \\
\text { Folk et al.'s (2002) } \\
\text { contingent } \\
\text { paradigm }\end{array}$ & $\begin{array}{l}\text { Lesion overlap } \\
\text { analysis }\end{array}$ & $\begin{array}{l}\text { rTPJ damage was associated to impairment of bottom-up } \\
\text { attentional orienting (but normal top-down orienting) }\end{array}$ \\
\hline $\begin{array}{l}\text { Singh and } \\
\text { Knight, }\end{array}$ & 1993 & $\begin{array}{l}\text { Bilateral } \\
\text { damage }\end{array}$ & $\begin{array}{l}\text { Acquired } \\
\text { brain injury }\end{array}$ & $\begin{array}{l}7 \text { TPJ, } 5 \text { lateral } \\
\text { parietal lesion, } 5 \\
\text { lateral parietal } \\
\text { and TPJ } \\
\text { damage, } 14 \mathrm{HC}\end{array}$ & EEG & - & - & - & - & - & $\begin{array}{l}\text { AlM self- } \\
\text { initiated } \\
\text { moveme } \\
\text { nts }\end{array}$ & $\begin{array}{l}\text { Self-paced switch } \\
\text { closures }\end{array}$ & $\begin{array}{l}\text { Movement-related } \\
\text { potentials }\end{array}$ & $\begin{array}{l}\text { Role of the superior parietal regions (and the rTPJ) for } \\
\text { movement preparation }\end{array}$ \\
\hline $\begin{array}{l}\text { Starkstein } \\
\text { et al., }\end{array}$ & 1992 & $\begin{array}{l}\text { Bilateral } \\
\text { damage }\end{array}$ & $\begin{array}{l}\text { Acquired } \\
\text { brain injury }\end{array}$ & $80 \mathrm{BD}$ (stroke) & CT & - & $\begin{array}{l}\text { AlM } \\
\text { anosognosi } \\
\text { a }\end{array}$ & - & - & - & - & $\begin{array}{l}\text { Anosognosia } \\
\text { questionnaire }\end{array}$ & Lesion volume & $\begin{array}{l}\text { Patients with mild or severe anosognosia typically had } \\
\text { temporoparietal damage compared to patients with no or } \\
\text { moderate anosognosia }\end{array}$ \\
\hline $\begin{array}{l}\text { Wawrzyni } \\
\text { ak et al., }\end{array}$ & 2018 & $\begin{array}{l}\text { Bilateral } \\
\text { damage }\end{array}$ & $\begin{array}{l}\text { Acquired } \\
\text { brain injury }\end{array}$ & $\begin{array}{l}10 \text { patients not } \\
\text { experiencing the } \\
\text { RHI (RHI-), } 37 \\
\text { experiencing the } \\
\text { RHI (RHI+), } 40 \\
\text { HC }\end{array}$ & FMRI & - & $\begin{array}{l}\text { AlM illusory } \\
\text { body- } \\
\text { ownership } \\
\text { feeling }\end{array}$ & - & - & - & - & RHI paradigm & $\begin{array}{l}\text { Lesion network- } \\
\text { symptom-mapping }\end{array}$ & $\begin{array}{l}\text { Differences between who suffers from RHI failure and not } \\
\text { were evident in the rTPJ, demonstrating the involvement of } \\
\text { the rTPJ in eliciting the illusory body-ownership feeling }\end{array}$ \\
\hline $\begin{array}{l}\text { Chechlac } \\
\mathrm{z} \text { et al., }\end{array}$ & 2014 & $\begin{array}{l}\text { Bilateral } \\
\text { damage }\end{array}$ & $\begin{array}{l}\text { Acquired } \\
\text { brain injury } \\
\text { (neglect) }\end{array}$ & $57 \mathrm{BD}, 100 \mathrm{HC}$ & MRI & $\begin{array}{l}\text { AIM spatial } \\
\text { attention }\end{array}$ & - & - & & $\begin{array}{l}\text { AlM } \\
\text { working } \\
\text { memory }\end{array}$ & - & $\begin{array}{l}\text { Corsi Block Task, } \\
\text { visual extinction, } \\
\text { and Apple } \\
\text { cancellation task }\end{array}$ & $\begin{array}{l}\text { Voxel-based } \\
\text { morphometry; tract- } \\
\text { wise lesion deficit } \\
\text { analysis }\end{array}$ & $\begin{array}{l}\text { Areas typically associated with neglect (e.g., the rTPJ) } \\
\text { may support visuospatial memory performance }\end{array}$ \\
\hline $\begin{array}{l}\text { Committe } \\
\text { ri et al., }\end{array}$ & 2015 & $\begin{array}{l}\text { Right } \\
\text { damage }\end{array}$ & $\begin{array}{l}\text { Acquired } \\
\text { brain injury } \\
\text { (neglect) }\end{array}$ & $40 \mathrm{RD}$ & FMRI & $\begin{array}{l}\text { AlM } \\
\text { visuospatial } \\
\text { attention }\end{array}$ & - & - & - & - & - & $\begin{array}{l}\text { Representational } \\
\text { neglect: Squares } \\
\text { test (familiar } \\
\text { places); familiar } \\
\text { objects (O'clock } \\
\text { test); Visual } \\
\text { extrapersonal } \\
\text { neglect (Letter } \\
\text { Cancellation Test, } \\
\text { Line Cancellation } \\
\text { Test, Wundt- }\end{array}$ & $\begin{array}{l}\text { Voxel-based lesion- } \\
\text { symptom mapping }\end{array}$ & $\begin{array}{l}\text { The TPJ emerged as significantly more involved in the } \\
\text { genesis of representational neglect for places }\end{array}$ \\
\hline
\end{tabular}




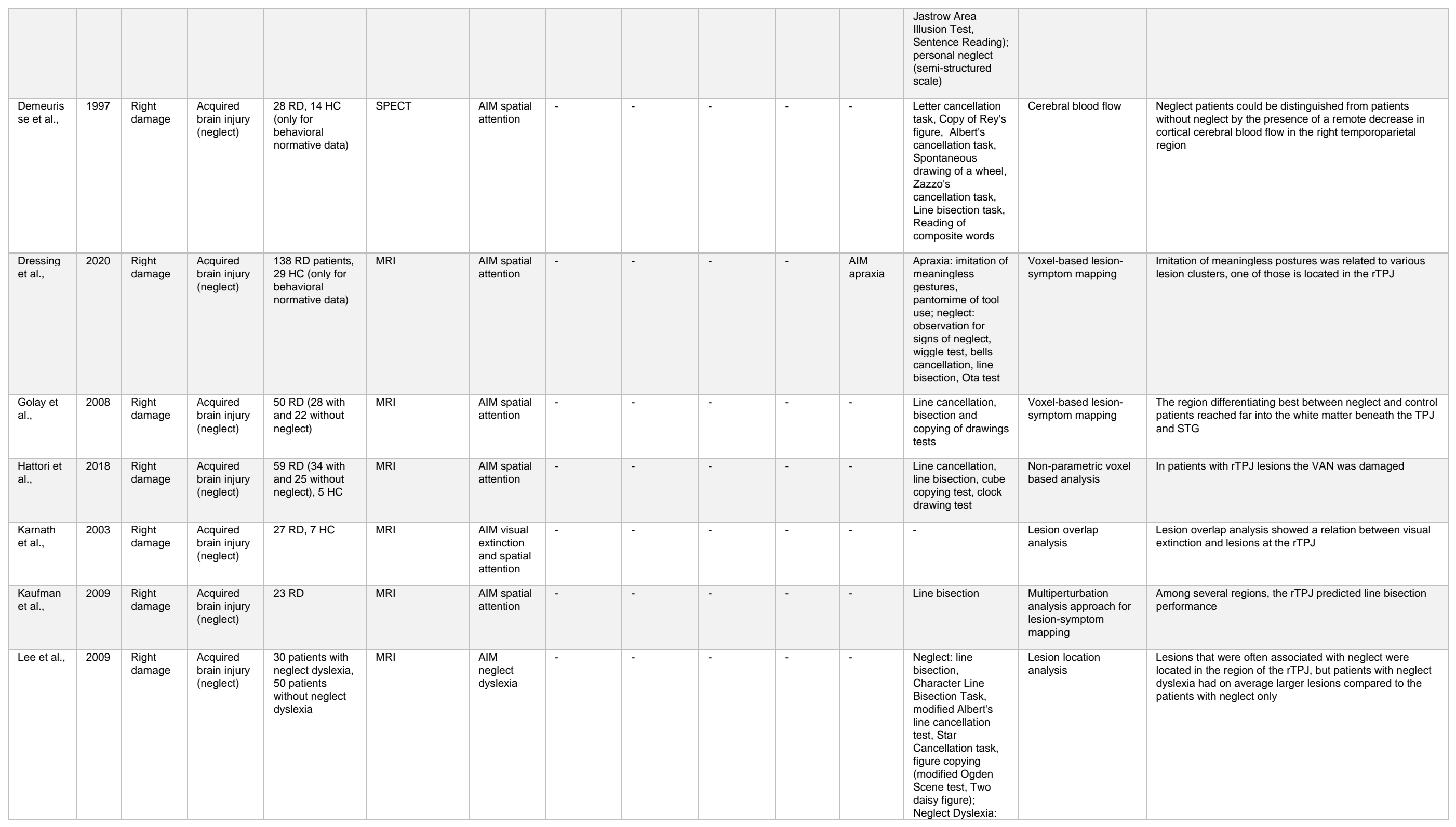




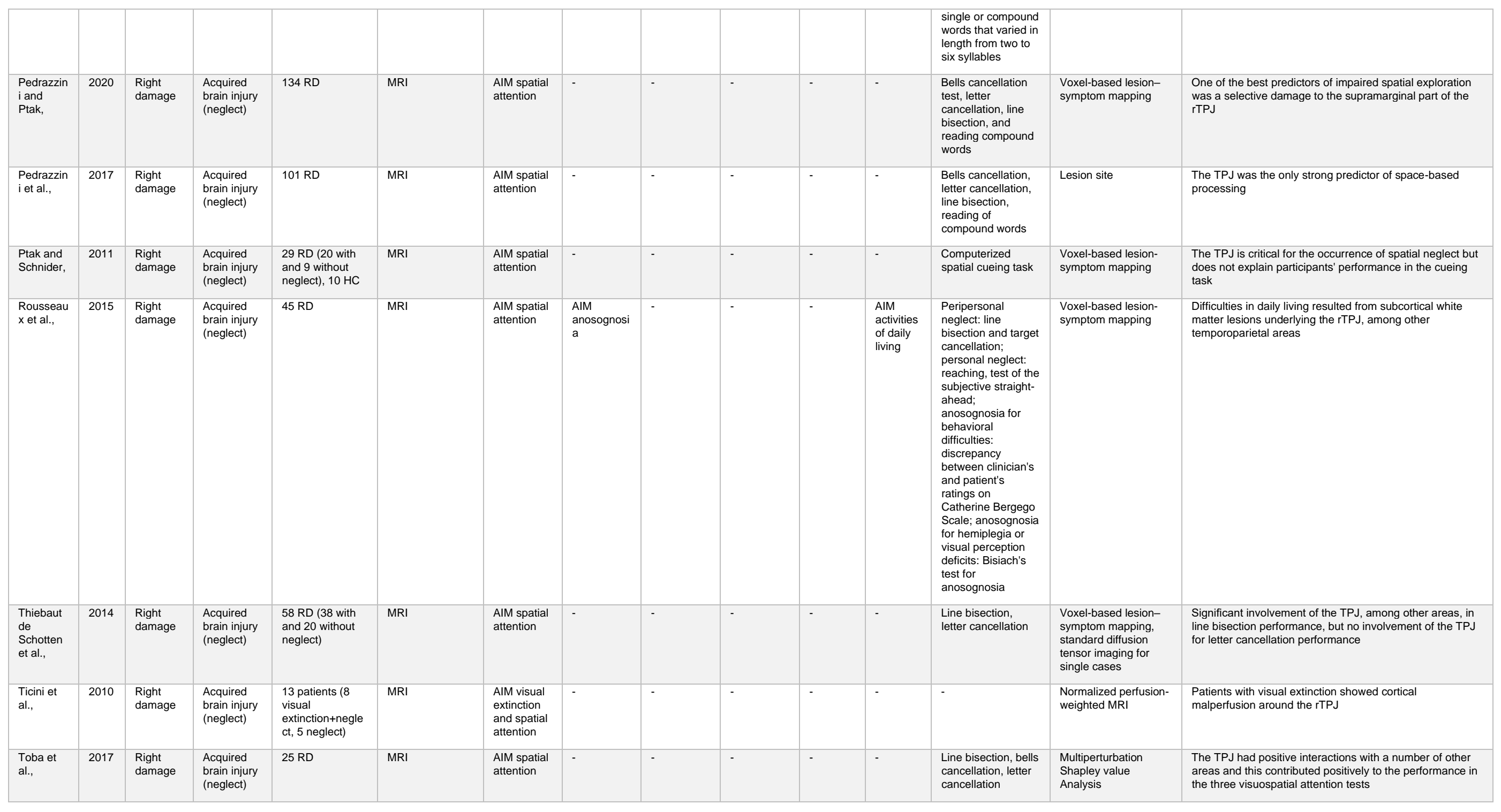




\begin{tabular}{|c|c|c|c|c|c|c|c|c|c|c|c|c|c|c|}
\hline $\begin{array}{l}\text { Baez et } \\
\text { al., }\end{array}$ & 2019 & $\begin{array}{l}\text { Neurode } \\
\text { generatio } \\
n\end{array}$ & $\begin{array}{l}\text { Neurodege } \\
\text { nerative } \\
\text { disease } \\
\text { (dementia } \\
\text { or cognitive } \\
\text { impairment) }\end{array}$ & $\begin{array}{l}16 \text { buFTD, } 13 \\
\text { bipolar disorder, } \\
\text { and } 22 \mathrm{HC}\end{array}$ & MRI & & $\begin{array}{l}\text { INC theory } \\
\text { of mind }\end{array}$ & - & $\begin{array}{l}\text { AlM } \\
\text { executive } \\
\text { functions }\end{array}$ & - & - & $\begin{array}{l}\text { Reading the Mind } \\
\text { in the Eyes test }\end{array}$ & $\begin{array}{l}\text { Voxel-based } \\
\text { morphometry }\end{array}$ & $\begin{array}{l}\text { bvFTD and bipolar patients showed an altered structural } \\
\text { activity in diverse regions; in bvFTD patients atrophy (i.e., } \\
\text { reduction of gray matter) of several regions (including the } \\
\text { rTPJ) was associated with theory of mind impairments }\end{array}$ \\
\hline $\begin{array}{l}\text { Blanc et } \\
\text { al., }\end{array}$ & 2015 & $\begin{array}{l}\text { Neurode } \\
\text { generatio } \\
n\end{array}$ & $\begin{array}{l}\text { Neurodege } \\
\text { nerative } \\
\text { disease } \\
\text { (dementia } \\
\text { or cognitive } \\
\text { impairment) }\end{array}$ & $\begin{array}{l}28 \text { proDLB, } 27 \\
\text { proAD, } 31 \mathrm{DLB} \\
54 \mathrm{AD}, 33 \mathrm{HC}\end{array}$ & MRI & - & - & - & - & - & - & - & Cortical thickness & $\begin{array}{l}\text { In the patients with DLB the cortical thinning was found } \\
\text { predominantly in the rTPJ, insula and other cortices, when } \\
\text { compared to HC }\end{array}$ \\
\hline $\begin{array}{l}\text { De Marco } \\
\text { et al., }\end{array}$ & 2019 & $\begin{array}{l}\text { Neurode } \\
\text { generatio } \\
\mathrm{n}\end{array}$ & $\begin{array}{l}\text { Neurodege } \\
\text { nerative } \\
\text { disease } \\
\text { (dementia } \\
\text { or cognitive } \\
\text { impairment) }\end{array}$ & $\begin{array}{l}86 \mathrm{MCl}, 35 \mathrm{AD}, \\
191 \mathrm{HC}\end{array}$ & fMRI & & & - & - & $\begin{array}{l}\text { INC } \\
\text { verbal } \\
\text { episodic } \\
\text { memory }\end{array}$ & - & Prose Memory Test & $\begin{array}{l}\text { Functional } \\
\text { connectivity }\end{array}$ & $\begin{array}{l}\text { A positive association was found between hippocampal } \\
\text { volumes and defautl mode network connectivity in the } \\
\text { rTPJ; an association between the rTPJ and verbal episodic } \\
\text { memory was found }\end{array}$ \\
\hline $\begin{array}{l}\text { Diez et } \\
\text { al., }\end{array}$ & 2019 & $\begin{array}{l}\text { Neurode } \\
\text { generatio } \\
\mathrm{n}\end{array}$ & $\begin{array}{l}\text { Neurodege } \\
\text { nerative } \\
\text { disease } \\
\text { (dementia } \\
\text { or cognitive } \\
\text { impairment) }\end{array}$ & $\begin{array}{l}30 \text { patients with } \\
\text { motor FND, } 30 \\
\text { HC }\end{array}$ & $\begin{array}{l}\text { Resting-state } \\
\text { fMRI }\end{array}$ & & $\begin{array}{l}\text { INC } \\
\text { awareness }\end{array}$ & - & - & - & - & $\begin{array}{l}\text { Screening for } \\
\text { Somatoform } \\
\text { Symptoms } \\
\text { Conversion } \\
\text { Disorder subscale } \\
\text { and patients Health } \\
\text { questionnaire }\end{array}$ & $\begin{array}{l}\text { Graph-theory } \\
\text { stepwise functional } \\
\text { connectivity }\end{array}$ & $\begin{array}{l}\text { FND patients had increased connectivity from motor } \\
\text { regions to the bilateral posterior insula, TPJ, middle } \\
\text { cingulate cortex and putamen. Interestingly, symptoms } \\
\text { severity correlated with enhanced SFC from the left } \\
\text { anterior insula to the right anterior insula and TPJ, } \\
\text { supplementary motor area and sensorimotor areas }\end{array}$ \\
\hline $\begin{array}{l}\text { Eslinger } \\
\text { et al., }\end{array}$ & 2012 & $\begin{array}{l}\text { Neurode } \\
\text { generatio } \\
\mathrm{n}\end{array}$ & $\begin{array}{l}\text { Neurodege } \\
\text { nerative } \\
\text { disease } \\
\text { (dementia } \\
\text { or cognitive } \\
\text { impairment) }\end{array}$ & $\begin{array}{l}26 \text { FTD (12 } \\
\text { bVFTD, } 7 \\
\text { progressive non- } \\
\text { fluent aphasia, } 7 \\
\text { semantic } \\
\text { dementia), } 16 \\
\text { HC }\end{array}$ & MRI & - & - & - & - & - & $\begin{array}{l}\text { AlM } \\
\text { apathy }\end{array}$ & $\begin{array}{l}\text { Apathy Evaluation } \\
\text { Scale }\end{array}$ & $\begin{array}{l}\text { Voxel-based } \\
\text { morphometry }\end{array}$ & $\begin{array}{l}\text { Apathy was significantly correlated with atrophic changes } \\
\text { in several regions, including the rTPJ in the subgroup of } \\
\text { bvFTD }\end{array}$ \\
\hline $\begin{array}{l}\text { Kang et } \\
\text { al., }\end{array}$ & 2019 & $\begin{array}{l}\text { Neurode } \\
\text { generatio } \\
\mathrm{n}\end{array}$ & $\begin{array}{l}\text { Neurodege } \\
\text { nerative } \\
\text { disease } \\
\text { (dementia } \\
\text { or cognitive } \\
\text { impairment) }\end{array}$ & $\begin{array}{l}26 \mathrm{ADCl}(18 \mathrm{MCl} \\
\text { and } 8 \text { dementia), } \\
28 \mathrm{LBCl} \text { (13 MCI } \\
\text { and } 15 \\
\text { dementia), and } \\
54 \text { mixed ADCl } \\
\text { and LBCI (17 } \\
\mathrm{MCl} \text { and } 37 \\
\text { dementia), } 38 \\
\mathrm{HC}\end{array}$ & MRI & $\begin{array}{l}\text { AIM } \\
\text { attention, } \\
\text { visuospatial } \\
\text { abilities }\end{array}$ & & $\begin{array}{l}\text { AlM } \\
\text { language }\end{array}$ & $\begin{array}{l}\text { AlM } \\
\text { executive } \\
\text { functions }\end{array}$ & $\begin{array}{l}\text { AlM } \\
\text { Verbal } \\
\text { learning, } \\
\text { memory }\end{array}$ & - & $\begin{array}{l}\text { Seoul } \\
\text { neuropsychological } \\
\text { screening battery }\end{array}$ & Cortical thickness & $\begin{array}{l}\text { ADCl and LBCI groups were independently associated } \\
\text { with cortical thinning in the association cortices, including } \\
\text { the bilateral TPJ, medial and lateral parietal, and DLPCCS } \\
\text { cortices. The mixed group, namely the group that had } \\
\text { concomitant ADCl and LBC, had additional cortical } \\
\text { thinning in widespread association cortices, including } \\
\text { bilateral TPJ }\end{array}$ \\
\hline $\begin{array}{l}\text { Luks et } \\
\text { al., }\end{array}$ & 2010 & $\begin{array}{l}\text { Neurode } \\
\text { generatio } \\
\mathrm{n}\end{array}$ & $\begin{array}{l}\text { Neurodege } \\
\text { nerative } \\
\text { disease } \\
\text { (dementia } \\
\text { or cognitive } \\
\text { impairment) }\end{array}$ & $\begin{array}{l}65 \text { mixed } \\
\text { neurodegenerati } \\
\text { ve diseases, } 22 \\
\text { HC }\end{array}$ & MRI & - & - & - & $\begin{array}{l}\text { INC } \\
\text { attentional } \\
\text { control }\end{array}$ & - & - & Flanker task & $\begin{array}{l}\text { Voxel-based } \\
\text { morphometry }\end{array}$ & $\begin{array}{l}\text { The atrophy in the TPJ-VLPFC network was associated } \\
\text { with slower attentional control on accurate trials }\end{array}$ \\
\hline $\begin{array}{l}\text { Qian et } \\
\text { al., }\end{array}$ & 2015 & $\begin{array}{l}\text { Neurode } \\
\text { generatio } \\
\mathrm{n}\end{array}$ & $\begin{array}{l}\text { Neurodege } \\
\text { nerative } \\
\text { disease } \\
\text { (dementia } \\
\text { or cognitive } \\
\text { impairment) }\end{array}$ & $\begin{array}{l}12 \mathrm{aMCl}, 16 \mathrm{AD}, \\
15 \mathrm{HC}\end{array}$ & fMRI & & & & & & & & $\begin{array}{l}\text { Functional } \\
\text { connectivity }\end{array}$ & $\begin{array}{l}\text { Decreased functional connectivity in the orbital ventral } \\
\text { frontal cortex and the TPJ in the AD patients, functional } \\
\text { connectivity was preserved in aMCl compared with HC. In } \\
\text { addition, gray matter density in the right ventral frontal } \\
\text { cortex was correlated with functional deterioration in the } \\
\text { rTPJ and ventral frontal cortex in AD }\end{array}$ \\
\hline
\end{tabular}




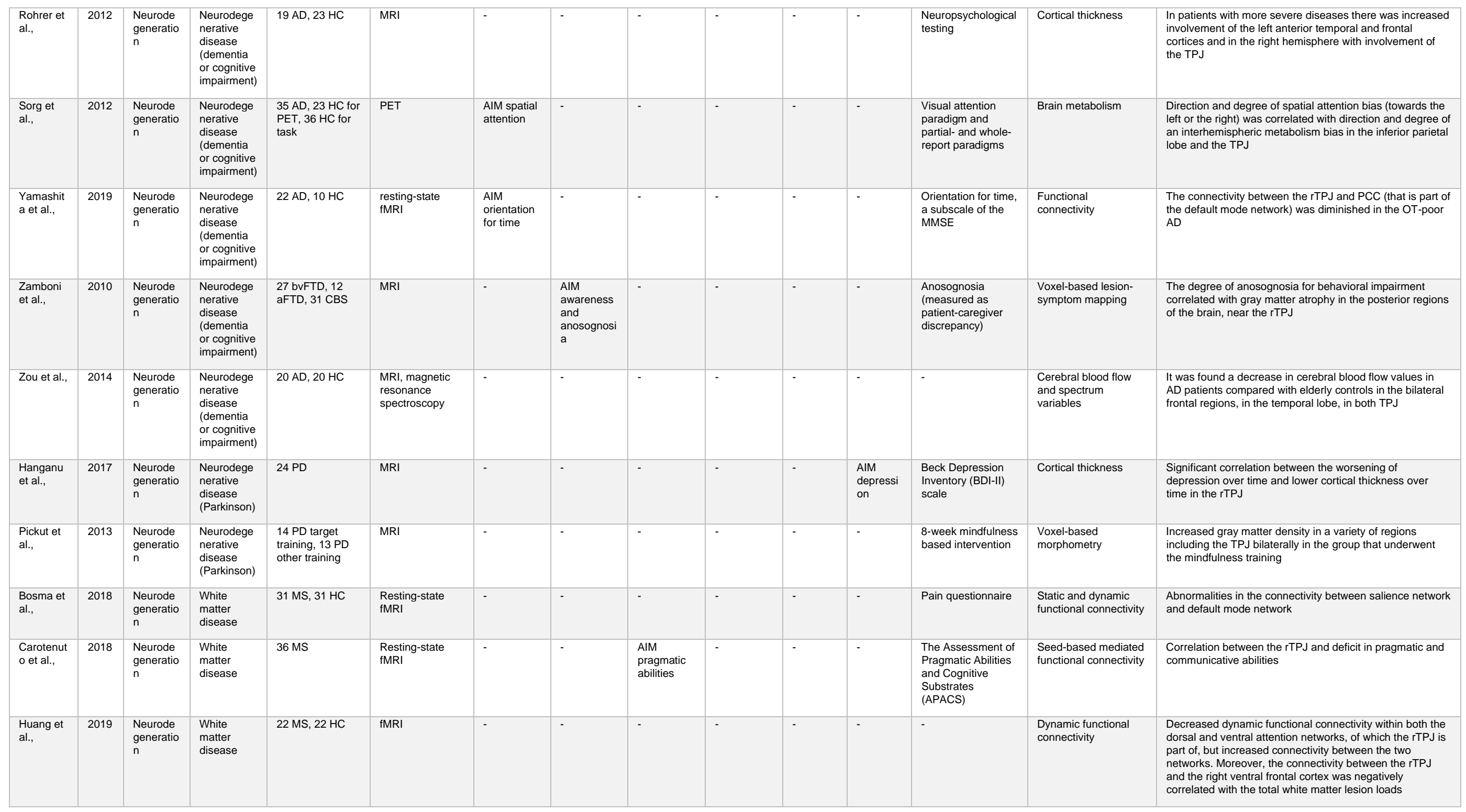




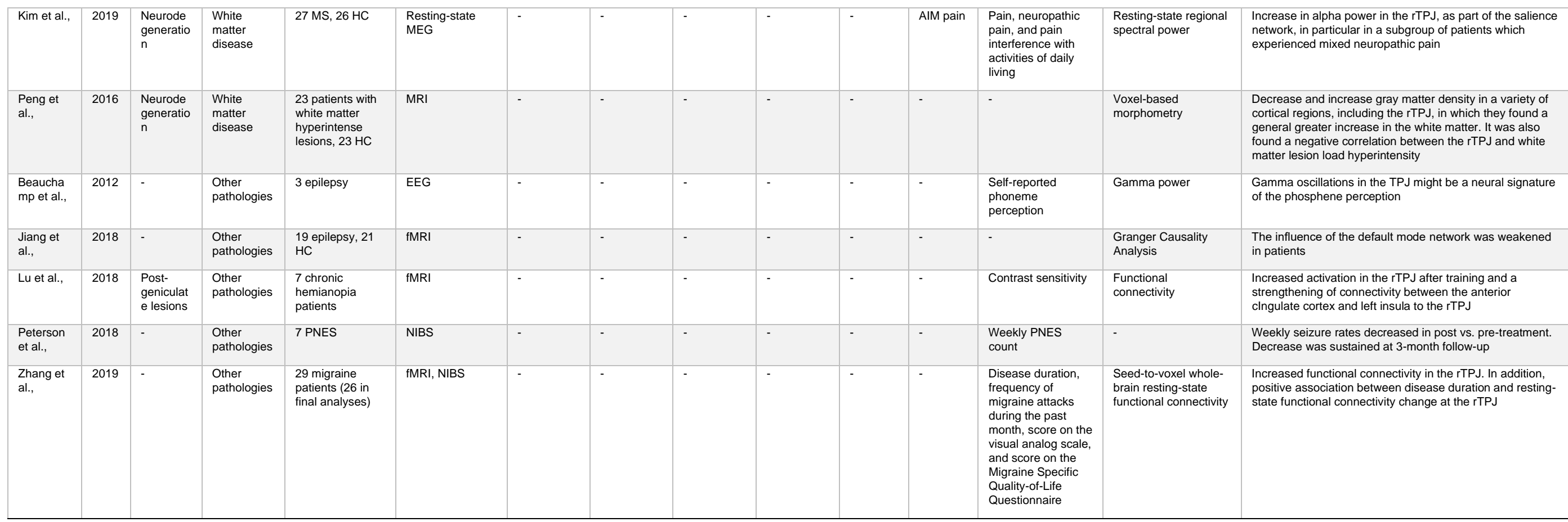

List of acronyms (Brain areas)

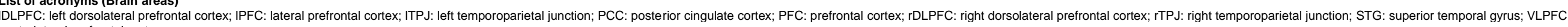
ventrolateral prefrontal cortex.

\section{List of acronyms (Other)}

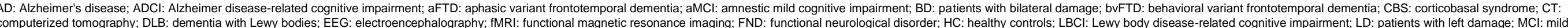

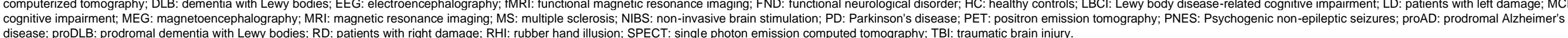

disease, proDLB: prodromal dementia with Lewy bodies; RD: patients with right damage; RHl: rubber hand illusion; SPECT: single photon emission computed tomography; TBI: traumatic brain injury.

Notes: For each study, the aim/s has/have been reported highlighting whether results were expected and in line with the hypotheses ("AlM" in Table) or were incidental ("INC" in Table). 


\section{Discussion}

The current study aimed at systematically investigating the rTPJ contribution in several neurological deficits, proposing how a wide variety of deficits may be a consequence of impairment in higher-order and domain-general predictive processing, possibly but not necessarily, related to a prediction network (Siman-Tov et al., 2019). This interpretation would unify several proposals and would be in contrast to the interpretation of rTPJ as having specific roles for specific cognitive functions.

Results confirmed our d shhypothesis anowed that rTPJ damage or degeneration, due to direct lesion or its disconnection from other brain regions, has an impact on several aspects of perception, cognition, and motion. In the next paragraphs, we will argue, in a large-scale perspective, that the ubiquitous association of rTPJ with manifold functional domains is supported by widespread connections with other brain structures/networks. It will be suggested how all these domains may underlie a common domain-general prediction-related processing. Then, we will discuss the implications of this view on the interpretation of traditional domains of cognitive functions both for basic and for clinical research.

\subsection{Unveiling the ubiquity of rTPJ}

Regardless of the possible bias in the literature that left some cognitive domains (e.g., language) not adequately covered, in the present review we have found a ubiquitous involvement of rTPJ across pathologies and cognitive tasks (see Table 1). In particular, it seems that damage to rTPJ can lead to impairment on almost any type of task, related to any main cognitive domain. As summarized in Table 1, findings from studies meeting the inclusion criteria showed how the damage or the disconnection of rTPJ has different functional cognitive consequences here clustered. In general, rTPJ seems crucial for attention, especially in spatial attention. The second greater cluster of deficits included studies on awareness and social cognition, considered as the inability or the difficulty of patients to maintain a proper self- or other-perception. Deficits in the representation of someone else's beliefs (i.e., ToM), difficulties to build up an appropriate body structural representation, and anosognosia are typical problems of this cluster. The systematic search shows, in addition, functional impairments involving other domains: motor deficits (including in this group also reduced goal-directed behaviors for a lack of motivation, i.e., apathy) and executive functions. Finally, a marginal number of studies established that rTPJ is linked to language and memory.

The sequelae of neurological disorders related to rTPJ can lead to interpreting all these deficits as the consequence of the disruption of specific domains. As such, within a modular view that assumes a one-to-one correspondence between brain structures and functions, it would be reasonable to infer that rTPJ plays a key role in all these domains: attention, awareness, social cognition, executive functions, memory, 
language, and motor functioning. However, in the era of networks, this "local" interpretation may sound simplistic since it neglects evidence showing how these impairments can result from a variety of other etiologies (e.g., attention impairments following frontal lesions). Hence, a large-scale approach may provide a better understanding of brain functioning, also outlining a multifaceted characterization and prediction of the consequences following neurological disorders.

Within a predictive framework, we argue that the ubiquitous involvement of rTPJ in cognition is supported anatomically and functionally by its connection with several brain areas, where it integrates diverse information and updates internal models and expectations regardless of the network in which it is involved. Classically, rTPJ is considered one of the core areas of the right-lateralized VAN, which controls reorienting of attention, whereas the DAN mainly controls sustained attention. Within the VAN, rTPJ processes stimuli that are unattended, but relevant for the task at hand. rTPJ is also assumed to respond to the salience of such stimuli (Corbetta et al., 2008). For example, it shows greater activation to infrequent targets in oddball tasks (Polich, 2007) and invalid rather than valid targets in a classical Posner task (Kincade et al., 2005). In a predictive view, unattended but relevant stimuli are highly salient because they violate the agent's expectations about their features (e.g., location in invalidly cued targets during the Posner cueing task), and therefore produce a greater prediction error. In line with Corbetta and his team (2008), Geng and Vossel (2013) support this view. They observed that rTPJ is active both during the oddball and the Posner cueing task. Regarding oddball tasks, TPJ is one of the most prominent neural generators of the P3, and particularly of the P3b component, which is elicited in response to deviant targets (Polich, 2007). The P3 is traditionally considered as an index of "contextual updating" reflecting the modification of the internal model of the task context based on external stimuli. Standard, frequent stimuli during oddball tasks generate strong expectations about task context, which are disconfirmed by the infrequent, deviant targets, that are highly salient and signal the need for updating the contextual expectation by integrating it with the new evidence. Geng and Vossel (2013) also interpreted the greater activation of rTPJ to the invalidly cued targets in the Posner cueing task as related to contextual updating, by a process that is analogous to that occurring for oddball tasks. These tasks activate rTPJ because this area allows the updating of the internal model of the environmental or task context based on the actual sensory inputs (Gastaldon et al., 2020). Such a change in expectation enables the initiation of actions that are appropriate to the task goal, even though during the task the stimuli have changed, or the cues are not valid.

The evidence accumulated through the aforementioned studies has led some authors to hypothesize that rTPJ, besides being part of the VAN and DMN, is also part of a larger, hierarchical prediction network involved in determining the internal model of the environment or task (Geng and Vossel, 2013). A subsequent meta-analysis (SimanTov et al., 2019) supported this hypothesis, by highlighting a set of brain regions involved in both perception and action prediction, encompassing both the VAN and 
the DAN and including rTPJ. This reinforces the hypothesis that rTPJ is a predictive hub where different cognitive processes and information types converge and are integrated; in relation to that, a disruption of rTPJ or its disconnection from other structures - as observed in heterogeneous neurological disorders - would have consequences on several other deficits. Importantly, it seems that the role of rTPJ in predictive processing is not necessarily related to its involvement in a specific prediction network. Indeed, in such a complex and dynamic system, the exact function of rTPJ seems defined within the network which is recruited by the ongoing activity (which in experimental terms, is the ongoing task). In other words, the context drives the specific coupling between rTPJ and other regions, thus recruiting the appropriate task-specific networks. For example, if we are engaged in an attentional task (e.g., the Posner cueing task), the VAN would be recruited; if instead we are engaged in a social cognition task, the DMN would be recruited. In both cases, rTPJ would be activated always as a key-hub for predictive processing, but for different purposes and together with different areas. The context- and network-dependent role of rTPJ allows for maximum flexibility of integration between different brain areas and cognitive processes. In this manner, context-dependent specific networks can use the integrative and contextual-updating function of rTPJ in different behavioral and cognitive contexts. In sum, the exact role of rTPJ is context- and network-driven, but its core function of integration and contextual updating integration does not change. We argue that the flexibility of rTPJ is the reason why we find its ubiquitous involvement across different cognitive domains: it fulfills a common function across a variety of different cognitive computations. In line with this, Fotopoulou (2014) proposed a predictive model for anosognosia for hemiplegia, reporting the existence of context-driven functional networks. This conceptualization enables us to go beyond the characterization of rTPJ as activated by peculiar, discrete, attention, or social cognition tasks contexts, and to appreciate its broader and domain-general role in comparing predictions about internal models of the environment or task to the actual external information and integrating it to the prediction themselves. This process may be impaired in neurological diseases that involve rTPJ and cause a variety of domaingeneral disorders.

Opposite to the advocated large-scale perspective, it has been claimed that rTPJ could be subdivided into different portions with different roles, such as related to attention or ToM (Scholz et al., 2009). If this very precise subdivision of rTPJ was confirmed for all the above-mentioned domains (to our knowledge, there is only limited evidence on this), one could argue that this would speak against our interpretation. Moreover, there is evidence of dissociations among the cognitive functions considered in this review, and that we traced back to damage to rTPJ or its connection (e.g., Happé et al., 1999), supporting a modular view of the mind that should be reflected in the brain architecture. We believe that both these possibilities would not alter the conclusions of the review. Considering the anatomical and functional parcellation of rTPJ, only two domains have been dissociated so far (spatial attention and theory of mind), while literature clearly 
shows the involvement of rTPJ in a plethora of cognitive and motor functions, showing the need for further studies to clarify the issue. Additionally, the proximity of two areas on two very different aspects of cognitive functions would speak in favor of similarity of the putative role of the areas and pointing to a gradient-like organization of such areas (Sansom and Livesey, 2009; Vázquez-Rodríguez et al., 2019).

Concerning the evidence of dissociation among the cognitive functions, although it has been largely claimed that connectionist accounts can explain dissociations even without modularity (Plaut, 1995), we would like to stress that the aim of the present review is not to challenge modularism, nor can the results from this review aim to clarify this aspect (a mixed organization of domain-specific modules and domain-general functioning would be also possible). The important point raised here is that an alternative view (based on several empirical findings) can pave new ways to design experiments both for basic research purposes and to interpret the diseases, and guide the design of new treatments, as we will suggest in the following paragraphs.

\subsection{Limitations}

The main limitation of the present review is that it only considers neurological populations and not healthy participants and psychiatric populations. The reason behind this choice is to be found in the aim of summarizing findings with a certain clinical relevance, to promote a predictive, more holistic view of neurological diseases. Circumscribing our work to neurological patients opens the field for future investigations on the role of rTPJ in healthy individuals. Another limit could be related to the inclusion of studies in which rTPJ was either directly lesioned or it was disconnected by other close regions; therefore, we cannot rule out whether the neuropsychological deficits are caused by rTPJ per se or by its disconnections with other brain areas. However, considering rTPJ as a crucial hub involved in predictive processing, damages that directly or indirectly impact rTPJ functioning are of interest to understand the role of this area. The investigation of a single hub (like rTPJ), rather than the whole prediction network, as recently highlighted by Siman-Tov and colleagues (2019), can also be seen as a limitation. However, rTPJ has particular clinical relevance, as described in the Introduction section. For example, it is frequently involved in right-hemisphere strokes in the territory of the middle cerebral artery and its lesioning often induces hemispatial neglect. Moreover, rTPJ is involved in cognitive functions apparently unrelated to each other (e.g., attention and ToM), suggesting the involvement of rTPJ in a plurality of networks (DAN, DMN; Corbetta et al., 2008; putative prediction network, Siman-Tov et al., 2019), which makes it susceptible to have a role in generating multiple cognitive and behavioral manifestations in neurological conditions.

Finally, it is important to underline that there are two limitations related to the interpretation we made in light of a predictive processing framework. First, as already pointed out in the Introduction, there are many theoretical interpretations and 
perspectives on the predictive processing framework or the bayesian brain (Clark, 2013) that could lead, in the end, to different interpretations or hypotheses. Second, predictive processing implies some specific mechanisms (e.g., model updates, propagation of prediction error) and the role of rTPJ in supporting them has not been fully clarified even if it seems it could be related to the update of internal models (Geng and Vossel, 2013). Given the nature of the evidence gathered in the present review, we believe that it would be too speculative to further detail on these two latter aspects. We believe the generic predictive processing framework we sketched already highlights the potential for future developments.

\subsection{Implications and future directions}

Considering neurological impairments engaging rTPJ as characterized by affecting domain-general predictive processing can help to shed new light on how disorders are understood. Under this perspective, the results highlighted in the current review can open new scenarios for basic research and for clinical applications in neurological disorders.

First, predictive processing has stimulated a paradigm shift in neuroscience that, in some cases, is leading to revising the functional organization of the brain into domains. This is affecting, for example, the distinction in those cognitive domains that have been traditionally interpreted as separate but that, under a predictive processing view, can be seen as highly connected (e.g., Doricchi et al., 2021; Fotopoulou, 2014).

Nevertheless, this perspective, although not new, is still not diffuse in clinical contexts. Most clinicians involved in the assessment and rehabilitation of neurological patients still base their hypotheses and interventions on traditional domains regarding brain functioning (e.g., memory, attention, mentalizing), and, to our knowledge, nobody uses clinical tools based on predictive processing perspectives. Although classification in functional domains has provided a method to decompose the complexity of brain functioning in "handy" components, the firm adherence to this approach can hamper the investigation of alternative domains or modalities of functioning of the brain, with both theoretical and practical consequences. Future works may clarify whether a predictive processing framework may be advocated as a general approach that could be applied to all domains of cognition, perception, and action (i.e., domain-general) or whether there are aspects of predictive processing that are domain-specific (see the Supplementary Materials for a rethink of domains related to rTPJ under the perspective of predictive processing). In the case of rTPJ, the degree of overlap of cognitive functions in such brain areas is so great that the effort of scientists to map cognitive modules is destined to lead to fruitless results. How can rTPJ contribute to all these functions? This may be an ill-posed question because it assumes the existence of such modules. Thus, future studies might explore the general role of rTPJ as part of a prediction network supporting non-conventional domains, transcending 
discrete modular limits, and tending towards new ontologies (Pessoa et al., 2022; Poldrack and Yarkoni, 2016).

Second, adopting a predictive processing framework can lead to very specific and clear-cut scientific questions that may further elucidate some long-lasting issues in the fields of cognitive impairments in neurological conditions. For example, it has been claimed that rTPJ may have a role in domain-general predictions, possibly as part of a prediction network (Siman-Tov et al., 2019). As Siman-Tov and colleagues (2019) claim, this network would be involved in higher-level predictions. But what is meant with "high-" or "low-" level of cognitive functions and "high-" or a "low-" level of prediction? What is meant for "domain-general" (what are the domains involved)?

Although labels may be sometimes fuzzy, the predictive framework can help to unveil whether traditional distinct functions have important shared aspects. For example, as recently showed by Doricchi and colleagues (2021), and commented by Garrido and Deouell (2021), neglect patients base their predictive behavior on statistical regularities that are related to the occurrence of sensory events on the right side of space during an auditory task; results of their study suggested how the pre-attentive reaction to the mismatch (i.e., the mismatch negativity, MMN) and the contextual updating (i.e., the P3) can be considered independent systems (Doricchi et al., 2021). The dissociation between the MMN and $\mathrm{P} 3$ responses may indicate that patients suffer from pre-attentive deficits, or, more specifically, of low precision weights that hinder the generation of predictive processes (Garrido and Deouell, 2021; Hohwy and Seth, 2020). It would be useful to understand whether specific biomarkers could be related not just to specific domains but could be extended also to other aspects of cognition, in line with an integrative and dynamic vision of cognitive functioning (Roger et al., 2022), as also discussed in the Supplementary Materials section.

Third, and in relation to the First point, the interpretation of the neurological impairments in the light of a unifying approach could be a parsimonious explanation of specific deficits and could pave the way for developing innovative neuropsychological tests for assessment and new neuropsychological rehabilitation protocols (e.g., treatments).

Concerning the assessment, a predictive processing view (not only related to rTPJ) supports the development of more extensive batteries to investigate clusters of deficits within and between domains (Corbetta et al., 2015), and suggest the importance to design different tasks that may be used to manipulate priors or precision and identify at what "stage" of predictive processing rTPJ plays a role. Whether the adoption of this framework has a clinical relevance is an empirical issue that could be disentangled in future studies comparing the actual assessment instruments with new assessment instruments designed in light of the predictive processing perspective.

Concerning the rehabilitation protocols, a predictive processing view can lead to the design of different treatments from several points of view. To give an example, the implementation of treatments in a predictive processing framework would stress the 
importance of improving predictive abilities in neurological patients, such as helping patients to identify and exploit probabilistic associations among sensory stimuli in the environment, or improving their ability to use contextual information to update their expectations. The idea that these deficits are not specific to individual perceptual or cognitive domains, but instead lie in mechanisms that link these domains, was previously suggested for generative models of language in schizophrenia, in which the combination of high- and low-level approaches was proposed for synergistic effects on overall cognitive and perceptual functioning (for similar considerations, see Brown and Kuperberg, 2015). Clearly, this speculative sketching of a model of predictive processing deficits in neurological disorders requires proper computational modeling and empirical testing at both neural and behavioral levels. This could have important implications for patients and for their daily functioning in a social environment, an environment that is highly complex, dynamic, and unpredictable, where an instant integration of information is required to efficiently respond to internal and external requests.

In addition, even if purely speculative to date, shifting to a domain-general predictive processing framework may help to understand one current limitation of the traditional neuropsychological treatments: the lack of generalization of the effects or better understanding the unexpected generalization to different domains (Anguera et al., 2013; Jacquin-Courtois et al., 2013). Assuming that it is possible to rehabilitate impaired predictive mechanisms (Brown and Kuperberg, 2015), benefits of a treatment based on the predictive processing framework might extend over a specific (treated) domain by virtue of the fact that predictive processing is a general property of brain functioning, common across domains.

As for the considerations made for assessment, it is an empirical issue that can be disentangled with experimental studies, whether this approach can lead to better and more effective rehabilitation treatments.

\section{Conclusion}

This review represents a systematic appraisal of studies that documented the involvement of rTPJ in neurological disorders, both in terms of its direct lesion or its disconnection from other brain regions. By overcoming the modular fragmentation of cognition following traditional domains (e.g., spatial attention, theory of mind, etc.), the present review sheds light on the possibility of interpreting rTPJ functioning within the overarching predicting processing framework, in particular considering rTPJ as a key hub involved in predictions for different behaviors. We suggest that the ubiquitous involvement of rTPJ in distinct domains is imputable to rTPJ being connected to several brain regions, with the functional role of integrating diverse information and updating internal models and expectations. A deeper understanding of the role of rTPJ within a predictive network paves new insights for interpreting neurological diseases 
and developing new treatments aimed at contrasting the impairment suffered by these patients.

\section{References}

Agosta, S., Magnago, D., Tyler, S., Grossman, E., Galante, E., Ferraro, F., Mazzini, N., Miceli, G., Battelli, L., 2017. The Pivotal Role of the Right Parietal Lobe in Temporal Attention. Journal of Cognitive Neuroscience 29, 805-815. https://doi.org/10.1162/jocn_a_01086

Anguera, J. A., Boccanfuso, J., Rintoul, J. L., Al-Hashimi, O., Faraji, F., Janowich, J., Kong, E., Larraburo, Y., Rolle, C., Johnston, E., \& Gazzaley, A. (2013). Video game training enhances cognitive control in older adults. Nature, 501(7465), 97-101. https://doi.org/10.1038/nature12486

Arcara, G., Bambini, V., 2016. A Test for the Assessment of Pragmatic Abilities and Cognitive Substrates (APACS): Normative Data and Psychometric Properties. Frontiers in Psychology 7, 70. https://doi.org/10.3389/fpsyg.2016.00070

Baez, S., Pinasco, C., Roca, M., Ferrari, J., Couto, B., García-Cordero, I., Ibañez, A., Cruz, F., Reyes, P., Matallana, D., Manes, F., Cetcovich, M., Torralva, T., 2019. Brain structural correlates of executive and social cognition profiles in behavioral variant frontotemporal dementia and elderly bipolar disorder. Neuropsychologia, The Biological Basis of Social Cognition During Development 126, 159-169. https://doi.org/10.1016/j.neuropsychologia.2017.02.012

Bardi, L., Kanai, R., Mapelli, D., Walsh, V., 2012. TMS of the FEF Interferes with Spatial Conflict. Journal of Cognitive Neuroscience 24, 1305-1313. https://doi.org/10.1162/jocn_a_00223

Beauchamp, M.S., Sun, P., Baum, S.H., Tolias, A.S., Yoshor, D., 2012. Electrocorticography links human temporoparietal junction to visual perception. Nat Neurosci 15, 957-959. https://doi.org/10.1038/nn.3131

Blanc, F., Colloby, S.J., Philippi, N., de Pétigny, X., Jung, B., Demuynck, C., Phillipps, C., Anthony, P., Thomas, A., Bing, F., Lamy, J., Martin-Hunyadi, C., O'Brien, J.T., Cretin, B., McKeith, I., Armspach, J.-P., Taylor, J.-P., 2015. Cortical Thickness in Dementia with Lewy Bodies and Alzheimer's Disease: A Comparison of Prodromal and Dementia Stages. PLoS One 10, e0127396. https://doi.org/10.1371/journal.pone.0127396

Boccia, M., Raimo, S., Di Vita, A., Battisti, A., Matano, A., Guariglia, C., Grossi, D., Palermo, L., 2020. Topological and hodological aspects of body representation in right brain damaged patients. Neuropsychologia 148, 107637. https://doi.org/10.1016/j.neuropsychologia.2020.107637 
Bosma, R.L., Kim, J.A., Cheng, J.C., Rogachov, A., Hemington, K.S., Osborne, N.R., Oh, J., Davis, K.D., 2018. Dynamic pain connectome functional connectivity and oscillations reflect multiple sclerosis pain. PAIN 159, 2267-2276. https://doi.org/10.1097/j.pain.0000000000001332

Brown, M., Kuperberg, G.R., 2015. A Hierarchical Generative Framework of Language Processing: Linking Language Perception, Interpretation, and Production Abnormalities in Schizophrenia. Front Hum Neurosci 9, 643. https://doi.org/10.3389/fnhum.2015.00643

Bzdok, D., Langner, R., Schilbach, L., Jakobs, O., Roski, C., Caspers, S., Laird, A.R., Fox, P.T., Zilles, K., Eickhoff, S.B., 2013. Characterization of the temporo-parietal junction by combining data-driven parcellation, complementary connectivity analyses, and functional decoding. Neurolmage 81, 381-392. https://doi.org/10.1016/j.neuroimage.2013.05.046

Campbell, B.C.V., Khatri, P., 2020. Stroke. The Lancet 396, 129-142. https://doi.org/10.1016/S0140-6736(20)31179-X

Carotenuto, A., Arcara, G., Orefice, G., Cerillo, I., Giannino, V., Rasulo, M., lodice, R., Bambini, V., 2018. Communication in Multiple Sclerosis: Pragmatic Deficit and its Relation with Cognition and Social Cognition. Archives of Clinical Neuropsychology 33, 194-205. https://doi.org/10.1093/arclin/acx061

Carter, R.M., Huettel, S.A., 2013. A nexus model of the temporal-parietal junction. Trends in Cognitive Sciences 17, 328-336. https://doi.org/10.1016/j.tics.2013.05.007

Caspers, S., Geyer, S., Schleicher, A., Mohlberg, H., Amunts, K., Zilles, K., 2006. The human inferior parietal cortex: Cytoarchitectonic parcellation and interindividual variability.

Neurolmage

33,

430-448.

https://doi.org/10.1016/j.neuroimage.2006.06.054

Chechlacz, M., Rotshtein, P., Humphreys, G.W., 2014. Neuronal substrates of Corsi Block span: Lesion symptom mapping analyses in relation to attentional competition and spatial bias. Neuropsychologia 64, 240-251. https://doi.org/10.1016/j.neuropsychologia.2014.09.038

Clark, A., 2013. Whatever next? Predictive brains, situated agents, and the future of cognitive science. Behavioral and Brain Sciences 36, 181-204. https://doi.org/10.1017/S0140525X12000477

Cohen-Zimerman, S., Khilwani, H., Smith, G.N.L., Krueger, F., Gordon, B., Grafman, J., 2021. The neural basis for mental state attribution: A voxel-based lesion mapping study. Human Brain Mapping 42, 65-79. https://doi.org/10.1002/hbm.25203 
Committeri, G., Piccardi, L., Galati, G., Guariglia, C., 2015. Where did you “left” Piazza del Popolo? At your "right" temporo-parietal junction. Cortex 73, 106-111. https://doi.org/10.1016/j.cortex.2015.08.009

Corbetta, M., Patel, G., Shulman, G.L., 2008. The Reorienting System of the Human Brain: From Environment to Theory of Mind. Neuron 58, 306-324. https://doi.org/10.1016/j.neuron.2008.04.017

Corbetta, M., Ramsey, L., Callejas, A., Baldassarre, A., Hacker, C.D., Siegel, J.S., Astafiev, S.V., Rengachary, J., Zinn, K., Lang, C.E., Connor, L.T., Fucetola, R., Strube, M., Carter, A.R., Shulman, G.L., 2015. Common Behavioral Clusters and Subcortical Anatomy in Stroke. Neuron 85, 927-941. https://doi.org/10.1016/j.neuron.2015.02.027

Corbetta, M., Shulman, G.L., 2011. Spatial Neglect and Attention Networks. Annual Review of Neuroscience 34, 569-599. https://doi.org/10.1146/annurev-neuro-061010113731

Corbetta, M., Shulman, G.L., 2002. Control of goal-directed and stimulus-driven attention in the brain. Nat Rev Neurosci 3, 201-215. https://doi.org/10.1038/nrn755

Corbetta, M., Siegel, J.S., Shulman, G.L., 2018. On the low dimensionality of behavioral deficits and alterations of brain network connectivity after focal injury. Cortex, In Memory of Professor Glyn Humphreys 107, 229-237. https://doi.org/10.1016/j.cortex.2017.12.017

De Marco, M., Ourselin, S., Venneri, A., 2019. Age and hippocampal volume predict distinct parts of default mode network activity. Sci Rep 9, 16075. https://doi.org/10.1038/s41598-019-52488-9

Decety, J., Lamm, C., 2007. The Role of the Right Temporoparietal Junction in Social Interaction: How Low-Level Computational Processes Contribute to Meta-Cognition. Neuroscientist 13, 580-593. https://doi.org/10.1177/1073858407304654

Demeurisse, G., Hublet, C., Paternot, J., Colson, C., Serniclaes, W., 1997. Pathogenesis of subcortical visuo-spatial neglect. A HMPAO SPECT study. Neuropsychologia 35, 731-735. https://doi.org/10.1016/S0028-3932(96)00126-1

Diez, I., Ortiz-Terán, L., Williams, B., Jalilianhasanpour, R., Ospina, J.P., Dickerson, B.C., Keshavan, M.S., Jr, W.C.L., Sepulcre, J., Perez, D.L., 2019. Corticolimbic fasttracking: enhanced multimodal integration in functional neurological disorder. $\mathrm{J}$ Neurol Neurosurg Psychiatry 90, 929-938. https://doi.org/10.1136/jnnp-2018-319657

Doricchi, F., Pinto, M., Pellegrino, M., Marson, F., Aiello, M., Campana, S., Tomaiuolo, F., Lasaponara, S., 2021. Deficits of hierarchical predictive coding in left spatial neglect. Brain Communications 3, fcab111. https://doi.org/10.1093/braincomms/fcab111 
Dressing, A., Martin, M., Beume, L.-A., Kuemmerer, D., Urbach, H., Kaller, C.P., Weiller, C., Rijntjes, M., 2020. The correlation between apraxia and neglect in the right hemisphere: A voxel-based lesion-symptom mapping study in 138 acute stroke patients. Cortex 132, 166-179. https://doi.org/10.1016/j.cortex.2020.07.017

Era, V., Aglioti, S.M., Candidi, M., 2020. Inhibitory Theta Burst Stimulation Highlights the Role of Left alPS and Right TPJ during Complementary and Imitative HumanAvatar Interactions in Cooperative and Competitive Scenarios. Cerebral Cortex 30, 1677-1687. https://doi.org/10.1093/cercor/bhz195

Eslinger, P.J., Moore, P., Antani, S., Anderson, C., Grossman, M., 2012. Apathy in frontotemporal dementia: behavioral and neuroimaging correlates. Behav Neurol 25, 127-136. https://doi.org/10.3233/BEN-2011-0351

Feldman, H., Friston, K., 2010. Attention, Uncertainty, and Free-Energy. Frontiers in Human Neuroscience 4, 215. https://doi.org/10.3389/fnhum.2010.00215

Fodor, J.A., Fodor, P.J.A., Fodor, J., 1983. The Modularity of Mind: An Essay on Faculty Psychology. MIT Press.

Fotopoulou, A., 2014. Time to get rid of the 'Modular' in neuropsychology: A unified theory of anosognosia as aberrant predictive coding. Journal of Neuropsychology 8 , 1-19. https://doi.org/10.1111/jnp.12010

Friston, K., 2012. Prediction, perception and agency. International Journal of Psychophysiology, Predictive information processing in the brain: Principles, neural mechanisms and models 83, 248-252. https://doi.org/10.1016/j.ijpsycho.2011.11.014

Friston, K., 2010. The free-energy principle: a unified brain theory? Nat Rev Neurosci 11, 127-138. https://doi.org/10.1038/nrn2787

Friston, K.J., 2019. Waves of prediction. PLOS Biology 17, e3000426. https://doi.org/10.1371/journal.pbio.3000426

Frith, C. d., Wolpert, D. m., Frith, U., Frith, C.D., 2003. Development and neurophysiology of mentalizing. Philosophical Transactions of the Royal Society of London. Series B: Biological Sciences 358, 459-473. https://doi.org/10.1098/rstb.2002.1218

Frucht, L., Perez, D.L., Callahan, J., MacLean, J., Song, P.C., Sharma, N., Stephen, C.D., 2021. Functional Dystonia: Differentiation From Primary Dystonia and Multidisciplinary Treatments. Frontiers in Neurology 11, 1972. https://doi.org/10.3389/fneur.2020.605262

Garrido, M.I., Deouell, L.Y., 2021. Unilateral neglect within the predictive processing framework. Brain Communications 3, fcab193. https://doi.org/10.1093/braincomms/fcab193 
Gastaldon, S., Arcara, G., Navarrete, E., Peressotti, F., 2020. Commonalities in alpha and beta neural desynchronizations during prediction in language comprehension and production. Cortex 133, 328-345. https://doi.org/10.1016/j.cortex.2020.09.026

Geng, J.J., Vossel, S., 2013. Re-evaluating the role of TPJ in attentional control: Contextual updating? Neuroscience \& Biobehavioral Reviews 37, 2608-2620. https://doi.org/10.1016/j.neubiorev.2013.08.010

Ghajar, J., Ivry, R.B., 2008. The Predictive Brain State: Timing Deficiency in Traumatic Brain Injury? Neurorehabil Neural Repair 22, 217-227. https://doi.org/10.1177/1545968308315600

Golay, L., Schnider, A., Ptak, R., 2008. Cortical and subcortical anatomy of chronic spatial neglect following vascular damage. Behavioral and Brain Functions 4, 43. https://doi.org/10.1186/1744-9081-4-43

Hanganu, A., Bruneau, M.-A., Degroot, C., Bedetti, C., Mejia-Constain, B., Lafontaine, A.-L., Chouinard, S., Monchi, O., 2017. Depressive symptoms in Parkinson's disease correlate with cortical atrophy over time. Brain and Cognition 111, 127-133. https://doi.org/10.1016/j.bandc.2016.11.001

Happé, F., Brownell, H., Winner, E., 1999. Acquired 'theory of mind' impairments following stroke. Cognition 70, 211-240. https://doi.org/10.1016/S00100277(99)00005-0

Hattori, T., Ito, K., Nakazawa, C., Numasawa, Y., Watanabe, M., Aoki, S., Mizusawa, H., Ishiai, S., Yokota, T., 2018. Structural connectivity in spatial attention network: reconstruction from left hemispatial neglect. Brain Imaging and Behavior 12, 309-323. https://doi.org/10.1007/s11682-017-9698-7

Hohwy, J., 2013. The Predictive Mind. Oxford University Press.

Hohwy, J., Seth, A., 2020. Predictive processing as a systematic basis for identifying the neural correlates of consciousness. Philosophy and the Mind Sciences 1. https://doi.org/10.33735/phimisci.2020.II.64

Huang, M., Zhou, F., Wu, L., Wang, B., Guo, L., Zhao, Y., Wan, H., Li, F., Zeng, X., Gong, H., 2019. White matter lesion loads associated with dynamic functional connectivity within attention network in patients with relapsing-remitting multiple sclerosis. Journal of Clinical Neuroscience 65, 59-65. https://doi.org/10.1016/j.jocn.2019.03.034

Jacquin-Courtois, S., O'Shea, J., Luauté, J., Pisella, L., Revol, P., Mizuno, K., Rode, G., \& Rossetti, Y. (2013). Rehabilitation of spatial neglect by prism adaptation. A peculiar expansion of sensorimotor after-effects to spatial cognition. Neuroscience and Biobehavioral Reviews, $37(4)$, 594-609. https://doi.org/10.1016/j.neubiorev.2013.02.007 
Jiang, L.-W., Qian, R.-B., Fu, X.-M., Zhang, D., Peng, N., Niu, C.-S., Wang, Y.-H., 2018. Altered attention networks and DMN in refractory epilepsy: A resting-state functional and causal connectivity study. Epilepsy \& Behavior 88, 81-86. https://doi.org/10.1016/j.yebeh.2018.06.045

Kang, S.W., Jeon, S., Yoo, H.S., Chung, S.J., Lee, P.H., Sohn, Y.H., Yun, M., Evans, A.C., Ye, B.S., 2019. Effects of Lewy body disease and Alzheimer disease on brain atrophy and cognitive dysfunction. Neurology 92, e2015-e2026. https://doi.org/10.1212/WNL.0000000000007373

Karnath, H.-O., Himmelbach, M., Küker, W., 2003. The cortical substrate of visual extinction. NeuroReport 14, 437-442.

Kaski, D., Quadir, S., Nigmatullina, Y., Malhotra, P.A., Bronstein, A.M., Seemungal, B.M., 2016. Temporoparietal encoding of space and time during vestibular-guided orientation. Brain 139, 392-403. https://doi.org/10.1093/brain/awv370

Kaufman, A., Serfaty, C., Deouell, L.Y., Ruppin, E., Soroker, N., 2009. Multiperturbation analysis of distributed neural networks: the case of spatial neglect. Hum Brain Mapp 30, 3687-3695. https://doi.org/10.1002/hbm.20797

Kim, J.A., Bosma, R.L., Hemington, K.S., Rogachov, A., Osborne, N.R., Cheng, J.C., Oh, J., Crawley, A.P., Dunkley, B.T., Davis, K.D., 2019. Neuropathic pain and pain interference are linked to alpha-band slowing and reduced beta-band magnetoencephalography activity within the dynamic pain connectome in patients with multiple sclerosis. $\quad$ PAIN 160 , 187-197. https://doi.org/10.1097/j.pain.0000000000001391

Kincade, J.M., Abrams, R.A., Astafiev, S.V., Shulman, G.L., Corbetta, M., 2005. An event-related functional magnetic resonance imaging study of voluntary and stimulusdriven orienting of attention. $J$ Neurosci 25, 4593-4604. https://doi.org/10.1523/JNEUROSCI.0236-05.2005

Kocagoncu, E., Klimovich-Gray, A., Hughes, L.E., Rowe, J.B., 2021. Evidence and implications of abnormal predictive coding in dementia. Brain J. Neurol. 144, 33113321. https://doi.org/10.1093/brain/awab254

Koster-Hale, J., Saxe, R., 2013. Theory of Mind: A Neural Prediction Problem. Neuron 79, 836-848. https://doi.org/10.1016/j.neuron.2013.08.020

Krall, S.C., Rottschy, C., Oberwelland, E., Bzdok, D., Fox, P.T., Eickhoff, S.B., Fink, G.R., Konrad, K., 2015. The role of the right temporoparietal junction in attention and social interaction as revealed by ALE meta-analysis. Brain Struct Funct 220, 587-604. https://doi.org/10.1007/s00429-014-0803-z

Kubit, B., Jack, A., 2013. Rethinking the role of the rTPJ in attention and social cognition in light of the opposing domains hypothesis: findings from an ALE-based 
meta-analysis and resting-state functional connectivity. Frontiers in Human Neuroscience 7, 323. https://doi.org/10.3389/fnhum.2013.00323

Lee, B.H., Suh, M.K., Kim, E.-J., Seo, S.W., Choi, K.M., Kim, G.-M., Chung, C.-S., Heilman, K.M., Na, D.L., 2009. Neglect dyslexia: Frequency, association with other hemispatial neglects, and lesion localization. Neuropsychologia 47, 704-710. https://doi.org/10.1016/j.neuropsychologia.2008.11.027

Leigh, R., Oishi, K., Hsu, J., Lindquist, M., Gottesman, R.F., Jarso, S., Crainiceanu, C., Mori, S., Hillis, A.E., 2013. Acute lesions that impair affective empathy. Brain 136, 2539-2549. https://doi.org/10.1093/brain/awt177

Lu, Q., Wang, X., Li, L., Qiu, B., Wei, S., Sabel, B.A., Zhou, Y., 2018. Visual rehabilitation training alters attentional networks in hemianopia: An fMRI study. Clinical Neurophysiology 129, 1832-1841. https://doi.org/10.1016/j.clinph.2018.05.027

Luks, T.L., Oliveira, M., Possin, K.L., Bird, A., Miller, B.L., Weiner, M.W., Kramer, J.H., 2010. Atrophy in two attention networks is associated with performance on a Flanker task in neurodegenerative disease. Neuropsychologia 48, 165-170. https://doi.org/10.1016/j.neuropsychologia.2009.09.001

Mandonnet, E., Cerliani, L., Siuda-Krzywicka, K., Poisson, I., Zhi, N., Volle, E., de Schotten, M.T., 2017. A network-level approach of cognitive flexibility impairment after surgery of a right temporo-parietal glioma. Neurochirurgie 63, 308-313. https://doi.org/10.1016/j.neuchi.2017.03.003

Martinaud, O., Besharati, S., Jenkinson, P.M., Fotopoulou, A., 2017. Ownership illusions in patients with body delusions: Different neural profiles of visual capture and disownership. Cortex, Confabulation and related disorders 87, 174-185. https://doi.org/10.1016/j.cortex.2016.09.025

Mengotti, P., Dombert, P.L., Fink, G.R., Vossel, S., 2017. Disruption of the Right Temporoparietal Junction Impairs Probabilistic Belief Updating. J Neurosci 37, 54195428. https://doi.org/10.1523/JNEUROSCI.3683-16.2017

Monai, E., Bernocchi, F., Bisio, M., Bisogno, A.L., Salvalaggio, A., Corbetta, M., 2020. Multiple Network Disconnection in Anosognosia for Hemiplegia. Frontiers in Systems Neuroscience 14, 21. https://doi.org/10.3389/fnsys.2020.00021

Ng, Y.S., Stein, J., Ning, M., Black-Schaffer, R.M., 2007. Comparison of Clinical Characteristics and Functional Outcomes of Ischemic Stroke in Different Vascular Territories. Stroke 38, 2309-2314. https://doi.org/10.1161/STROKEAHA.106.475483

Oldrati, V., Ferrari, E., Butti, N., Cattaneo, Z., Borgatti, R., Urgesi, C., Finisguerra, A., 2021. How social is the cerebellum? Exploring the effects of cerebellar transcranial direct current stimulation on the prediction of social and physical events. Brain Struct. Funct. 226, 671-684. https://doi.org/10.1007/s00429-020-02198-0 
Page, M.J., McKenzie, J.E., Bossuyt, P.M., Boutron, I., Hoffmann, T.C., Mulrow, C.D., Shamseer, L., Tetzlaff, J.M., Akl, E.A., Brennan, S.E., Chou, R., Glanville, J., Grimshaw, J.M., Hróbjartsson, A., Lalu, M.M., Li, T., Loder, E.W., Mayo-Wilson, E., McDonald, S., McGuinness, L.A., Stewart, L.A., Thomas, J., Tricco, A.C., Welch, V.A., Whiting, P., Moher, D., 2021. The PRISMA 2020 statement: an updated guideline for reporting systematic reviews. BMJ 372, n71. https://doi.org/10.1136/bmj.n71

Palop, J.J., Chin, J., Mucke, L., 2006. A network dysfunction perspective on neurodegenerative diseases. Nature 443, 768-773. https://doi.org/10.1038/nature05289

Park, B., Fareri, D., Delgado, M., Young, L., 2021. The role of right temporoparietal junction in processing social prediction error across relationship contexts. Social Cognitive and Affective Neuroscience 16, 772-781. https://doi.org/10.1093/scan/nsaa072

Patel, G.H., Sestieri, C., Corbetta, M., 2019. The evolution of the temporoparietal junction and posterior superior temporal sulcus. Cortex 118, 38-50. https://doi.org/10.1016/j.cortex.2019.01.026

Patra, J., Bhatia, M., Suraweera, W., Morris, S.K., Patra, C., Gupta, P.C., Jha, P., 2015. Exposure to Second-Hand Smoke and the Risk of Tuberculosis in Children and Adults: A Systematic Review and Meta-Analysis of 18 Observational Studies. PLOS Medicine 12, e1001835. https://doi.org/10.1371/journal.pmed.1001835

Pedrazzini, E., Ptak, R., 2020. The neuroanatomy of spatial awareness: a large-scale region-of-interest and voxel-based anatomical study. Brain Imaging Behav 14, 615626. https://doi.org/10.1007/s11682-019-00213-5

Pedrazzini, E., Ptak, R., 2019. Damage to the right temporoparietal junction, but not lateral prefrontal or insular cortex, amplifies the role of goal-directed attention. Sci Rep 9, 306. https://doi.org/10.1038/s41598-018-36537-3

Pedrazzini, E., Schnider, A., Ptak, R., 2017. A neuroanatomical model of space-based and object-centered processing in spatial neglect. Brain Struct Funct 222, 3605-3613. https://doi.org/10.1007/s00429-017-1420-4

Peng, Y., Li, S., Zhuang, Y., Liu, X., Wu, L., Gong, H., Liu, D., Zhou, F., 2016. Density abnormalities in normal-appearing gray matter in the middle-aged brain with white matter hyperintense lesions: a DARTEL-enhanced voxel-based morphometry study. Clin Interv Aging 11, 615-622. https://doi.org/10.2147/CIA.S98409

Pessoa, L., Medina, L., Desfilis, E., 2022. Refocusing neuroscience: moving away from mental categories and towards complex behaviours. Philosophical Transactions of the Royal Society B: Biological Sciences 377, 20200534. https://doi.org/10.1098/rstb.2020.0534 
Peterson, K.T., Kosior, R., Meek, B.P., Ng, M., Perez, D.L., Modirrousta, M., 2018. Right Temporoparietal Junction Transcranial Magnetic Stimulation in the Treatment of Psychogenic Non-epileptic Seizures: A Case Series. Psychosomatics 59, 601-606. https://doi.org/10.1016/j.psym.2018.03.001

Pezzulo, G., Zorzi, M., Corbetta, M., 2021. The secret life of predictive brains: what's spontaneous activity for? Trends in Cognitive Sciences 25, 730-743. https://doi.org/10.1016/j.tics.2021.05.007

Pickut, B.A., Van Hecke, W., Kerckhofs, E., Mariën, P., Vanneste, S., Cras, P., Parizel, P.M., 2013. Mindfulness based intervention in Parkinson's disease leads to structural brain changes on MRI: A randomized controlled longitudinal trial. Clinical Neurology and Neurosurgery 115, 2419-2425. https://doi.org/10.1016/j.clineuro.2013.10.002

Pisella, L., Alahyane, N., Blangero, A., Thery, F., Blanc, S., Pelisson, D., 2011. Righthemispheric dominance for visual remapping in humans. Philosophical Transactions of the Royal Society B: Biological Sciences 366, 572-585. https://doi.org/10.1098/rstb.2010.0258

Plaut, D.C., 1995. Double dissociation without modularity: Evidence from connectionist neuropsychology. J. Clin. Exp. Neuropsychol. 17, 291-321. https://doi.org/10.1080/01688639508405124

Poldrack, R.A., Yarkoni, T., 2016. From brain maps to cognitive ontologies: informatics and the search for mental structure. Annu Rev Psychol 67, 587-612. https://doi.org/10.1146/annurev-psych-122414-033729

Polich, J., 2007. Updating P300: An integrative theory of P3a and P3b. Clinical Neurophysiology 118, 2128-2148. https://doi.org/10.1016/j.clinph.2007.04.019

Ptak, R., Schnider, A., 2011. The attention network of the human brain: Relating structural damage associated with spatial neglect to functional imaging correlates of spatial attention. Neuropsychologia 49, 3063-3070. https://doi.org/10.1016/j.neuropsychologia.2011.07.008

Qian, S., Zhang, Z., Li, B., Sun, G., 2015. Functional-structural degeneration in dorsal and ventral attention systems for Alzheimer's disease, amnestic mild cognitive impairment. Brain Imaging Behav 9, 790-800. https://doi.org/10.1007/s11682-0149336-6

Roger, E., Banjac, S., Thiebaut de Schotten, M., Baciu, M., 2022. Missing links: The functional unification of language and memory (LUM). Neuroscience \& Biobehavioral Reviews 133, 104489. https://doi.org/10.1016/j.neubiorev.2021.12.012

Rohrer, J.D., Rossor, M.N., Warren, J.D., 2012. Alzheimer's pathology in primary progressive aphasia. Neurobiol Aging 33, 744-752. https://doi.org/10.1016/j.neurobiolaging.2010.05.020 
Rousseaux, M., Allart, E., Bernati, T., Saj, A., 2015. Anatomical and psychometric relationships of behavioral neglect in daily living. Neuropsychologia 70, 64-70. https://doi.org/10.1016/j.neuropsychologia.2015.02.011

Sansom, S.N., Livesey, F.J., 2009. Gradients in the brain: the control of the development of form and function in the cerebral cortex. Cold Spring Harb. Perspect. Biol. 1, a002519. https://doi.org/10.1101/cshperspect.a002519

Scholz, J., Triantafyllou, C., Whitfield-Gabrieli, S., Brown, E.N., Saxe, R., 2009. Distinct Regions of Right Temporo-Parietal Junction Are Selective for Theory of Mind $\begin{array}{lllll}\text { and Exogenous Attention. PLOS ONE 4, e4869. } & \text {. }\end{array}$ https://doi.org/10.1371/journal.pone.0004869

Shallice, T., 1988. From Neuropsychology to Mental Structure. Cambridge University Press, Cambridge. https://doi.org/10.1017/CBO9780511526817

Shomstein, S., Lee, J., Behrmann, M., 2010. Top-down and bottom-up attentional guidance: investigating the role of the dorsal and ventral parietal cortices. Exp Brain Res 206, 197-208. https://doi.org/10.1007/s00221-010-2326-z

Siman-Tov, T., Granot, R.Y., Shany, O., Singer, N., Hendler, T., Gordon, C.R., 2019. Is there a prediction network? Meta-analytic evidence for a cortical-subcortical network likely subserving prediction. Neurosci Biobehav Rev 105, 262-275. https://doi.org/10.1016/j.neubiorev.2019.08.012

Singh, J., Knight, R.T., 1993. Effects of posterior association cortex lesions on brain potentials preceding self-initiated movements. J. Neurosci. 13, 1820-1829. https://doi.org/10.1523/JNEUROSCI.13-05-01820.1993

Smith, R., Badcock, P., Friston, K.J., 2021. Recent advances in the application of predictive coding and active inference models within clinical neuroscience. Psychiatry and Clinical Neurosciences 75, 3-13. https://doi.org/10.1111/pcn.13138

Sorg, C., Myers, N., Redel, P., Bublak, P., Riedl, V., Manoliu, A., Perneczky, R., Grimmer, T., Kurz, A., Förstl, H., Drzezga, A., Müller, H.J., Wohlschläger, A.M., Finke, K., 2012. Asymmetric loss of parietal activity causes spatial bias in prodromal and mild Alzheimer's disease. Biol Psychiatry 71, 798-804. https://doi.org/10.1016/j.biopsych.2011.09.027

Starkstein, S.E., Fedoroff, J.P., Price, T.R., Leiguarda, R., Robinson, R.G., 1992. Anosognosia in patients with cerebrovascular lesions. A study of causative factors. Stroke 23, 1446-1453. https://doi.org/10.1161/01.STR.23.10.1446

Swanson, L.R., 2016. The Predictive Processing Paradigm Has Roots in Kant. Frontiers in Systems Neuroscience 10, 79. https://doi.org/10.3389/fnsys.2016.00079 
Thiebaut de Schotten, M., Tomaiuolo, F., Aiello, M., Merola, S., Silvetti, M., Lecce, F., Bartolomeo, P., Doricchi, F., 2014. Damage to White Matter Pathways in Subacute and Chronic Spatial Neglect: A Group Study and 2 Single-Case Studies with Complete Virtual "In Vivo" Tractography Dissection. Cerebral Cortex 24, 691-706. https://doi.org/10.1093/cercor/bhs351

Thompson, K.G., Hanes, D.P., Bichot, N.P., Schall, J.D., 1996. Perceptual and motor processing stages identified in the activity of macaque frontal eye field neurons during visual search. Journal of Neurophysiology 76, 4040-4055. https://doi.org/10.1152/jn.1996.76.6.4040

Ticini, L.F., de Haan, B., Klose, U., Nägele, T., Karnath, H.-O., 2010. The Role of Temporo-parietal Cortex in Subcortical Visual Extinction. Journal of Cognitive Neuroscience 22, 2141-2150. https://doi.org/10.1162/jocn.2009.21315

Toba, M.N., Zavaglia, M., Malherbe, C., Moreau, T., Rastelli, F., Kaglik, A., Valabrègue, R., Pradat-Diehl, P., Hilgetag, C.C., Valero-Cabré, A., 2020. Game theoretical mapping of white matter contributions to visuospatial attention in stroke patients with hemineglect. Hum Brain Mapp 41, 2926-2950. https://doi.org/10.1002/hbm.24987

Vallar, G., 2007. Spatial Neglect, Balint-Homes' and Gerstmann's Syndrome, and Other Spatial Disorders. CNS Spectrums 12, 527-536. https://doi.org/10.1017/S1092852900021271

Vallar, G., Calzolari, E., 2018. Chapter 14 - Unilateral spatial neglect after posterior parietal damage, in: Vallar, G., Coslett, H.B. (Eds.), Handbook of Clinical Neurology, The Parietal Lobe. Elsevier, pp. 287-312. https://doi.org/10.1016/B978-0-444-636225.00014-0

Vázquez-Rodríguez, B., Suárez, L.E., Markello, R.D., Shafiei, G., Paquola, C., Hagmann, P., Heuvel, M.P. van den, Bernhardt, B.C., Spreng, R.N., Misic, B., 2019. Gradients of structure-function tethering across neocortex. Proc. Natl. Acad. Sci. 116, 21219-21227. https://doi.org/10.1073/pnas. 1903403116

Verleger, R., Heide, W., Butt, C., Kömpf, D., 1994. Reduction of P3b in patients with temporo-parietal lesions. Cognitive Brain Research 2, 103-116. https://doi.org/10.1016/0926-6410(94)90007-8

Vossel, S., Geng, J.J., Fink, G.R., 2014. Dorsal and Ventral Attention Systems: Distinct Neural Circuits but Collaborative Roles. Neuroscientist 20, 150-159. https://doi.org/10.1177/1073858413494269

Vossel, S., Thiel, C.M., Fink, G.R., 2006. Cue validity modulates the neural correlates of covert endogenous orienting of attention in parietal and frontal cortex. Neurolmage 32, 1257-1264. https://doi.org/10.1016/j.neuroimage.2006.05.019 
Wawrzyniak, M., Klingbeil, J., Zeller, D., Saur, D., Classen, J., 2018. The neuronal network involved in self-attribution of an artificial hand: A lesion network-symptommapping study. Neurolmage 166, 317-324. https://doi.org/10.1016/j.neuroimage.2017.11.011

Wells, G., O'Connell, D., Peterson, J., Welch, W., Losos, M., Tugwell, P., 2011. The Newcastle-Ottawa Scale (NOS) for assessing the quality of nonrandomised studies in meta-analyses.

Wilson, B., Winegardner, J., Heugten, C. van, Ownsworth, T., 2017. Neuropsychological Rehabilitation: The International Handbook, $1^{\circ}$ edizione. ed. Routledge, London ; New York.

Wolpe, N., Zhang, J., Nombela, C., Ingram, J.N., Wolpert, D.M., Rowe, J.B., 2018. Sensory attenuation in Parkinson's disease is related to disease severity and dopamine dose. Sci Rep 8, 15643. https://doi.org/10.1038/s41598-018-33678-3

Yamashita, K.-I., Uehara, T., Prawiroharjo, P., Yamashita, K., Togao, O., Hiwatashi, A., Taniwaki, Y., Utsunomiya, H., Matsushita, T., Yamasaki, R., Kira, J.-I., 2019. Functional connectivity change between posterior cingulate cortex and ventral attention network relates to the impairment of orientation for time in Alzheimer's disease patients. Brain Imaging Behav 13, 154-161. https://doi.org/10.1007/s11682018-9860-x

Young, L., Camprodon, J.A., Hauser, M., Pascual-Leone, A., Saxe, R., 2010. Disruption of the right temporoparietal junction with transcranial magnetic stimulation reduces the role of beliefs in moral judgments. PNAS 107, 6753-6758. https://doi.org/10.1073/pnas.0914826107

Zamboni, G., Grafman, J., Krueger, F., Knutson, K.M., Huey, E.D., 2010. Anosognosia for behavioral disturbances in frontotemporal dementia and corticobasal syndrome: A voxel-based morphometry study. Dement Geriatr Cogn Disord 29, 88-96. https://doi.org/10.1159/000255141

Zhang, Y., Liu, J., Li, H., Yan, Z., Liu, X., Cao, J., Park, J., Wilson, G., Liu, B., Kong, J., 2019. Transcutaneous auricular vagus nerve stimulation at $1 \mathrm{~Hz}$ modulates locus coeruleus activity and resting state functional connectivity in patients with migraine: An fMRI study. Neurolmage: Clinical 24, 101971. https://doi.org/10.1016/j.nicl.2019.101971

Zou, J.-X., Wang, M.-J., Lei, X.-J., Chen, X.-G., 2014. 3.0T MRI arterial spin labeling and magnetic resonance spectroscopy technology in the application of Alzheimer's disease. Experimental Gerontology 60, 31-36. https://doi.org/10.1016/j.exger.2014.09.009 


\section{Identification of studies via databases and registers}

\begin{tabular}{|c|c|}
\hline $\begin{array}{l}\text { Records identified through } \\
\text { databases }(n=539) \text { : }\end{array}$ & $\begin{array}{l}\text { Records removed before } \\
\text { screening: }\end{array}$ \\
\hline $\begin{array}{l}\text { Pubmed }(n=169) \\
\text { Psyclnfo }(n=151) \\
\text { Embase }(n=219)\end{array}$ & $\begin{array}{l}\text { Duplicate records removed } \\
(\mathrm{n}=340)\end{array}$ \\
\hline
\end{tabular}
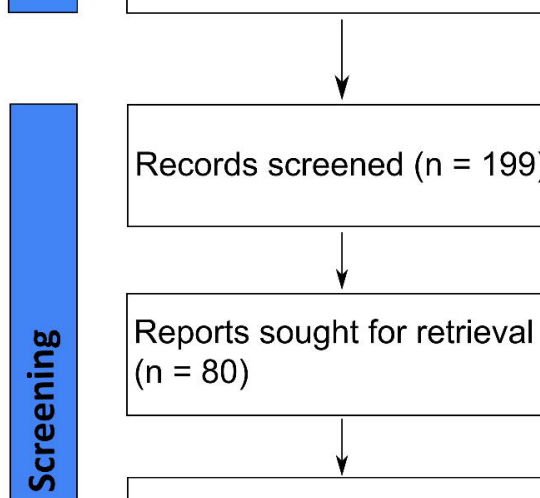

Records excluded $(n=119)$
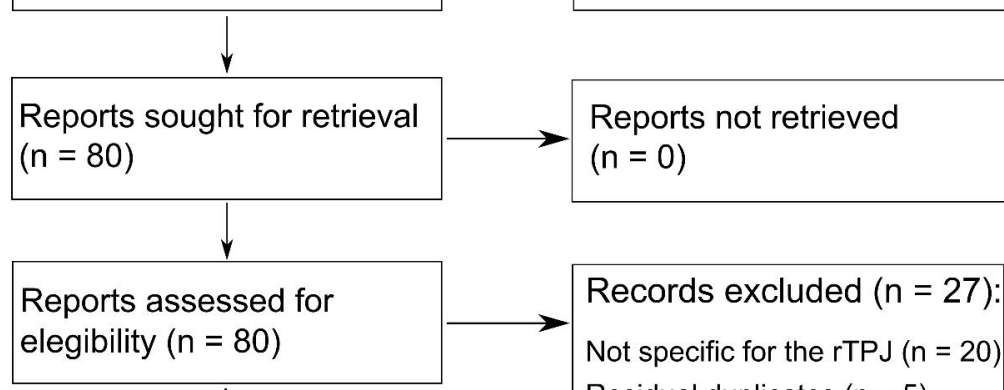

Records excluded $(n=27)$ :

Not specific for the rTPJ $(n=20)$

Residual duplicates $(n=5)$

No population of interest $(n=2)$

\section{Identification of studies via other methods}

Records identified from:

Citation searching $(n=1)$

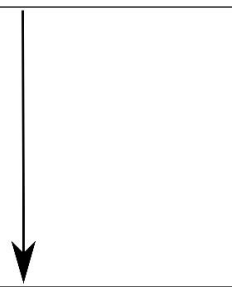

Reports sought for retrieval $(n=1)$

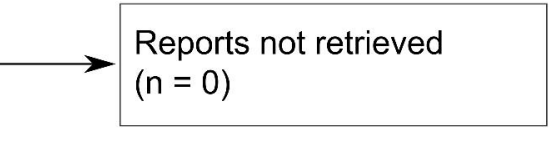

Reports assessed for elegibility $(n=1)$

Reports included in review

$(n=54)$ 